University of South Florida

DIGITAL COMMONS

@ UNIVERSITY OF SOUTH FLORIDA
Digital Commons @ University of

South Florida

$5-1-2013$

\title{
Recommendations for Yield-to-Bus Traffic Control Devices and Bus Pullout Bays Design Characteristics
}

CUTR

Follow this and additional works at: https://digitalcommons.usf.edu/cutr_nctr

\section{Recommended Citation}

"Recommendations for Yield-to-Bus Traffic Control Devices and Bus Pullout Bays Design Characteristics," National Center for Transit Research (NCTR) Report No. CUTR-NCTR-RR-2013-01, Center for Urban Transportation Research, University of South Florida, 2013.

DOI: https://doi.org/10.5038/CUTR-NCTR-RR-2013-01

Available at: https://scholarcommons.usf.edu/cutr_nctr/108

This Technical Report is brought to you for free and open access by the National Center for Transit Research (NCTR) Archive (2000-2020) at Digital Commons @ University of South Florida. It has been accepted for inclusion in Research Reports by an authorized administrator of Digital Commons @ University of South Florida. For more information, please contact digitalcommons@usf.edu. 


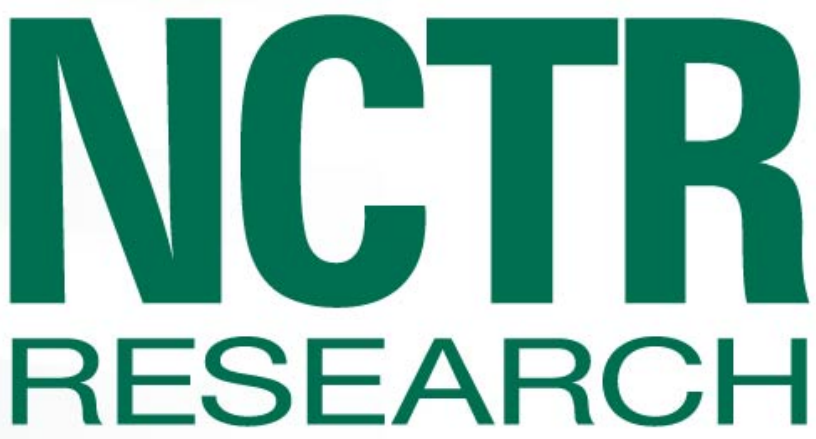

\section{Recommendations for Yield-to-Bus Traffic Control Devices and Bus Pullout Bays Design Characteristics BDK85 977-33}

April 2013

Final Report

PREPARED FOR:

Florida Department of Transportation

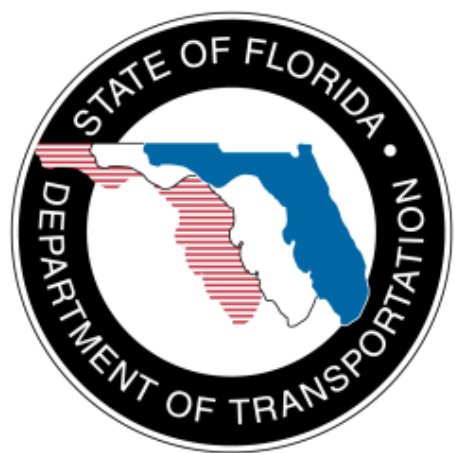




\section{Recommendations for Yield-to-Bus Traffic Control Devices and Bus Pullout Bays Design Characteristics BDK85 977-33}

Prepared for:



Florida Department of Transportation Fred Heery, P.E., Co-Project Manager Victor Wiley, CPM, Co-Project Manager

Prepared by:

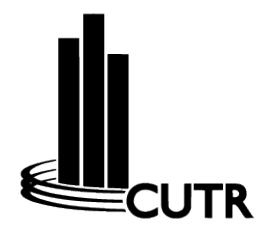

USF Center for Urban Transportation Research Pei-Sung Lin, Ph.D., P.E., PTOE, Program Director Aldo Fabregas, Ph.D., Research Associate Serkan Gunpinar, Graduate Assistant Osiel Perez-Angon, Graduate Assistant Bijan Behzadi, P.E., PTOE, Adjunct Instructor

Final Report

April 2013 


\section{Disclaimer}

The opinions, findings, and conclusions expressed in this publication are those of the authors and not necessarily those of the State of Florida Department of Transportation. 


\section{Metric Conversion}

\begin{tabular}{|c|c|c|c|c|}
\hline SYMBOL & $\begin{array}{l}\text { WHEN YOU } \\
\text { KNOW }\end{array}$ & MULTIPLY BY & TO FIND & SYMBOL \\
\hline \multicolumn{5}{|c|}{ LENGTH } \\
\hline in & inches & 25.4 & millimeters & $\mathrm{mm}$ \\
\hline ft & feet & 0.305 & meters & $\mathrm{m}$ \\
\hline yd & yards & 0.914 & meters & $\mathrm{m}$ \\
\hline mi & miles & 1.61 & kilometers & $\mathrm{km}$ \\
\hline \multicolumn{5}{|c|}{ VOLUME } \\
\hline floz & fluid ounces & 29.57 & milliliters & $\mathrm{mL}$ \\
\hline gal & gallons & 3.785 & liters & L \\
\hline $\mathrm{ft}^{3}$ & cubic feet & 0.028 & cubic meters & $\mathrm{m}^{3}$ \\
\hline$y d^{3}$ & cubic yards & 0.765 & cubic meters & $\mathrm{m}^{3}$ \\
\hline \multicolumn{5}{|c|}{ NOTE: volumes greater than $1000 \mathrm{~L}$ shall be shown in $\mathrm{m}^{3}$} \\
\hline \multicolumn{5}{|c|}{ MASS } \\
\hline oz & ounces & 28.35 & grams & $\mathrm{g}$ \\
\hline lb & pounds & 0.454 & kilograms & $\mathrm{kg}$ \\
\hline $\mathbf{T}$ & short tons $(2000 \mathrm{lb})$ & 0.907 & $\begin{array}{l}\text { megagrams } \\
\text { (or "metric } \\
\text { ton") }\end{array}$ & Mg (or "t") \\
\hline \multicolumn{5}{|c|}{ TEMPERATURE (exact degrees) } \\
\hline${ }^{\circ} \mathbf{F}$ & Fahrenheit & $\begin{array}{c}5(\mathrm{~F}-32) / 9 \\
\text { or }(\mathrm{F}-32) / 1.8\end{array}$ & Celsius & ${ }^{\circ} \mathrm{C}$ \\
\hline
\end{tabular}




\section{Technical Report Documentation}

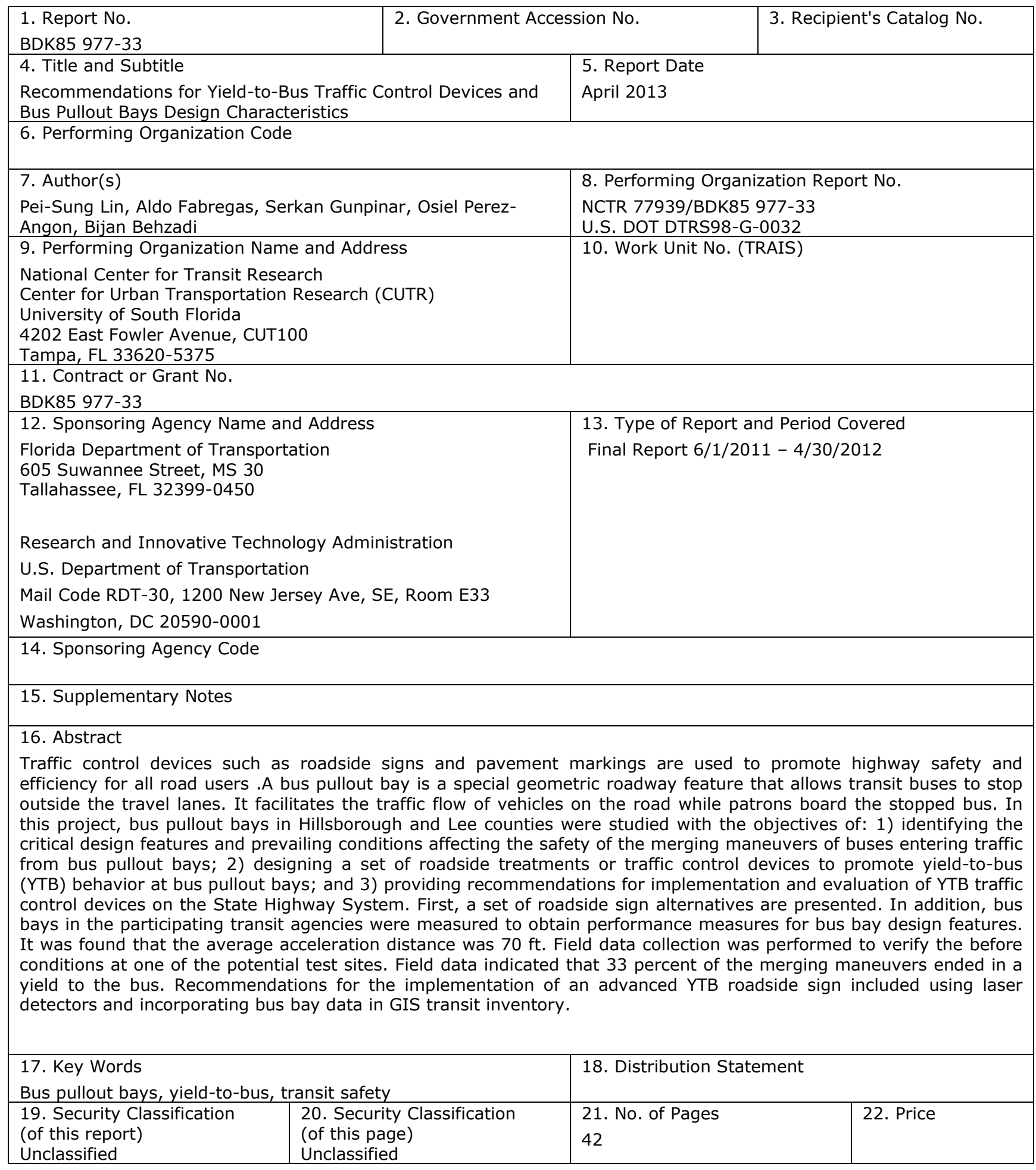




\section{Acknowledgments}

\section{Florida Department of Transportation}

Fred Heery, Deputy State Traffic Operations Engineer, Co-Project Manger

Victor Wiley, Transit Safety Programs Manager, Co-Project Manager

Mark Wilson, State Traffic Operations Engineer

Gary Thompson, District 7 Traffic Operations Engineer

L.K. Nandam, District 1 Traffic Operations Engineer

Richard Morrow, District 5 Traffic Operations Engineer

\section{Hillsborough Area Regional Transit}

David Kelsey, Hillsborough Area Regional Transit, Safety and Security Analyst

\section{Lee County Transit}

Paul Goyette, Operations Manager

Robert Southall, Senior Operations Supervisor

Mitch Riley, Senior Engineer

\section{Lynx}

Baunie McConnell, Director of Risk and Safety

Mira Bourova, GIS Coordinator Planning Department

\section{Center for Urban Transportation Research}

Joel Volinski, NCTR Director

Amber Reep, Senior Research Associate 


\section{Executive Summary}

In this project, yield-to-bus (YTB) roadside signage was designed and proposed for future implementation. Geometric factors of bus pullout bay designs were collected, analyzed, and geo-referenced for future use. The study of roadside treatments, an analysis of the geometric characteristics of bus pullout bays, and field data collection were aimed at achieving the following objectives:

- Identify the critical design features and prevailing conditions affecting the safety of the merging maneuvers of buses entering traffic from bus pullout bays.

- Design a set of roadside treatments or traffic control devices to promote YTB behavior at bus pullout bays.

- Provide recommendations for implementation and evaluation of YTB traffic control devices on the State Highway System.

The candidate signage for experimentation was designed based on meetings and discussions with the project team and State and District traffic operation engineers. The candidate designs are presented in Figure A. However, The text-only sign is recommended for implementation and testing since it does not contain symbols that require driver's interpretation.

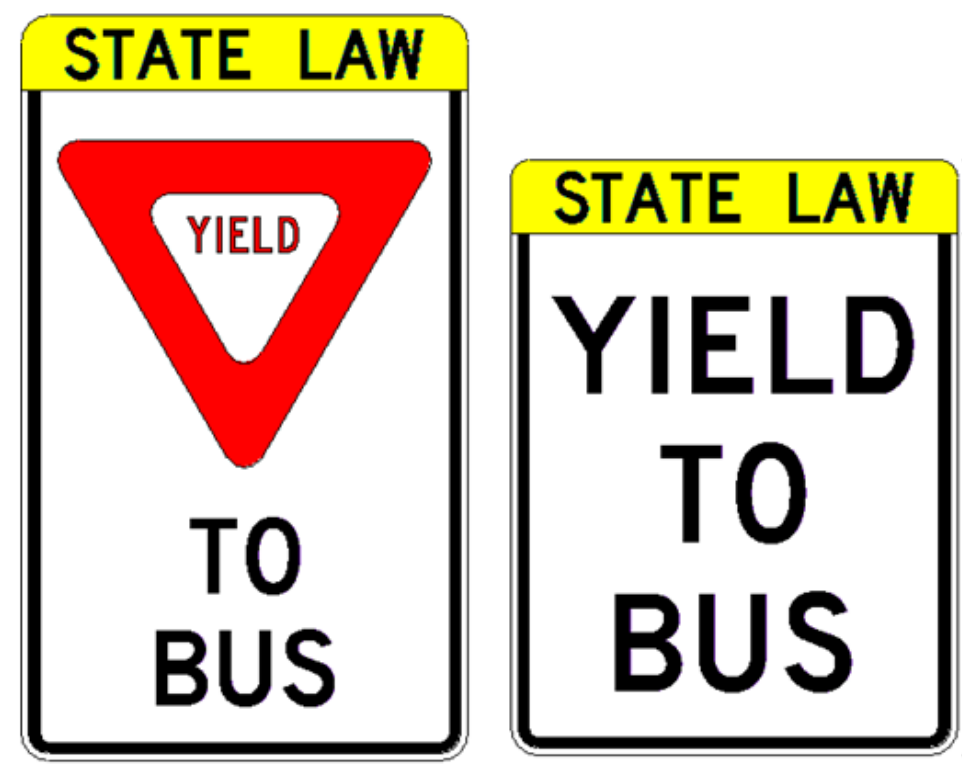

Figure A: Candidate Designs for YTB Treatments

Geometric factors of bus pullout bays in Hillsborough and Lee Counties were collected, analyzed, and geo-referenced for future use. Based on the collected information, the overall mean acceleration distance was $70 \mathrm{ft}$. This will allow merging speeds between 35 and 50 $\mathrm{mph}$ for four $\mathrm{fps}^{2}$ and eight $\mathrm{fps}^{2}$ acceleration rates, respectively. Figure $\mathrm{B}$ presents a summary of the mean acceleration distance by speed limit. It can be observed that the bus bay design allows for more acceleration distances at higher speed limits. 




Figure B: Boxplot of Acceleration Distance by Speed Limit

The re-entry speed for the bus bays was established as the minimum of the calculated reentry speed and the speed limit of the facility, using a conservative acceleration rate of 4 $\mathrm{fps}^{2}$ and a moderate to high acceleration rate of $8 \mathrm{fps}^{2}$. Figure $\mathrm{C}$ presents the performance of the bus pullout bay design under the conservative and moderate scenarios. The performance was calculated as the ratio of the re-entry speed to the through-direction speed limit. A ratio of 100 percent indicates that the bus bay pullout bay design allows the bus to reach the target through speed. For the conservative acceleration scenario, 47 percent of the bus pullout bays are below the 80 percent line (re-entry speed is 80 percent of the speed limit). With the moderate to high acceleration rate scenario, only 4.7 percent are below the 80 percent line.

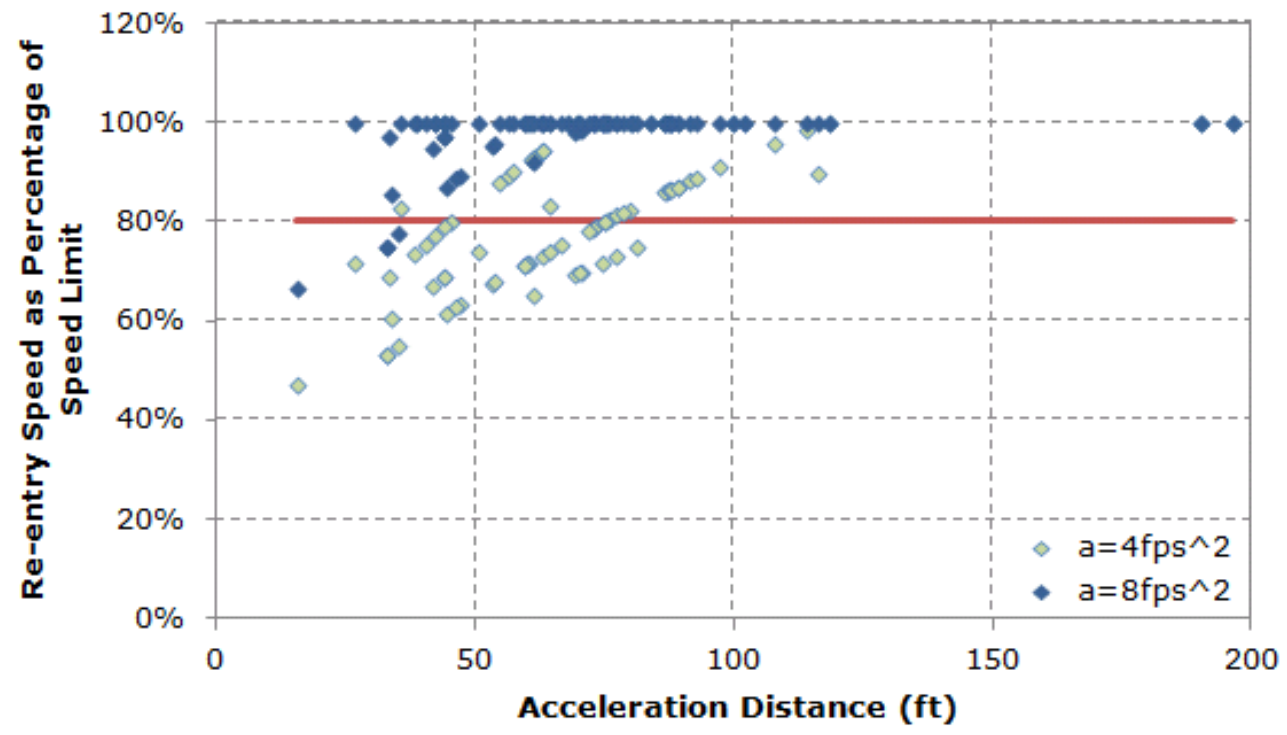

Figure C: Bus Pullout Bay Design Performance Scenarios 
The re-entry time was calculated based upon the time the bus turning lamps were activated. The overall re-entry time was about 36 seconds, with a standard deviation of 32 seconds. The average re-entry time for merging maneuvers ending in a yield to the bus was 29 seconds, with a standard deviation of 13 seconds. In Figure D, it can be observed that the variance of the re-entry time reduced when motorists yielded to the bus. This can have a positive effect on transit travel time reliability and schedule adherence.

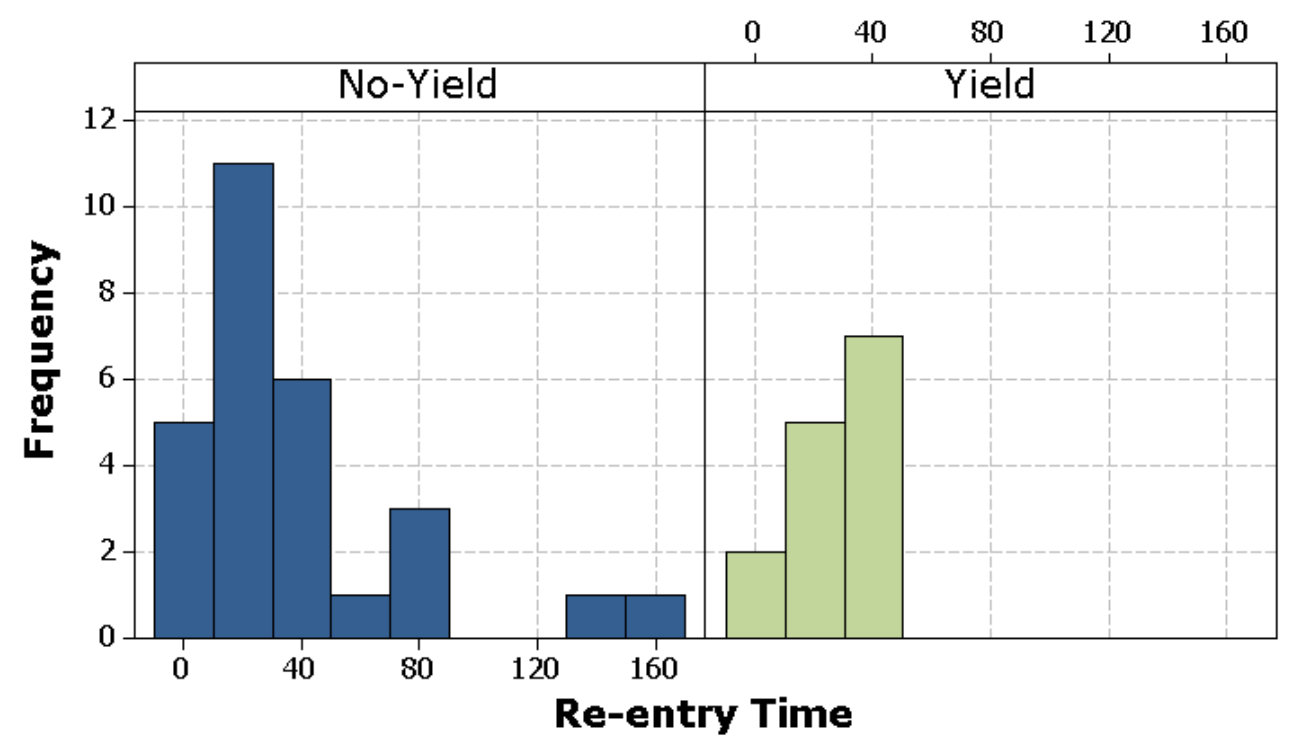

Figure D: Histogram of Re-entry Time by YTB Behavior

\section{Conclusions}

- The preferred traffic control device to support the YTB law is the roadside sign. Roadside signs provide a more direct message to the motorists than pavement markings.

- The average acceleration distance was $70 \mathrm{ft}$. with a moderate acceleration rate of 4 $\mathrm{fps}^{2}$. This will allow buses to reach a re-entry speed of $35 \mathrm{mph}$.

- Based on detailed observations on one of the test sites, the percentage of merging maneuvers that ended in a yield to the bus was found to be 33 percent. However, 67 percent of those maneuvers ended in the transit bus waiting for an acceptable gap in traffic.

- The overall average re-entry time was 36 seconds in this study. For merging maneuvers ending in a yield, the average re-entry time was 29 seconds. For merging maneuvers where motorists did not yield to the bus, the average re-entry time was 39 seconds. Therefore, an average operational efficiency in transit operations of up to 25 percent could be achieved as more motorists yield to the bus.

- The standard deviation for the re-entry delay for maneuvers ending in a yield to the bus was 13 seconds; for maneuvers with no-yield the standard deviation was 39 seconds. This can have a significant influence on travel time reliability. 
- The percentage of maneuvers with conflicts was 93 percent. Two types of conflicts were observed, car with accelerating bus, and car with lane-changing car.

\section{Recommendations}

- It is recommended that transit agencies incorporate some traffic features as part of their GIS database. This can include whether the bus stop is in a bus bay or in a turning lane, bus pullout bay geometry, proximity of upstream access point, etc. This can help to provide a better evaluation for transit safety and operations with respect to traffic.

- YTB sign placement should meet the guidelines contained in the MUTCD. YTB signs are recommended to be placed at $100 \mathrm{ft}$ upstream from the beginning of the bus bay when the posted speed limit is $45 \mathrm{mph}$ or less.

- It is recommended that the sign messages for YTB roadside treatments are tested using a survey instrument to ensure that the sign wording is interpreted correctly.

- For testing purposes, it is recommended to use solar-powered flashing beacons with a non-intrusive detection system, such as the one proposed using LIDAR devices. For field implementation a more robust solution using sensors can be developed.

- It is recommended to incorporate additional transit agencies for the field testing of YTB roadside signs with flashers.

- Accident data from transit agencies can be a valuable source of information for roadway design improvement. It is recommended to standardize transit incident reporting, especially location information in the form of milepost or geographic coordinates. 


\section{Table of Contents}

Disclaimer ....................................................................................................... ii

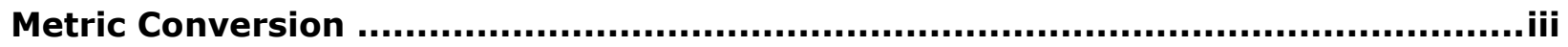





Executive Summary........................................................................................... vi

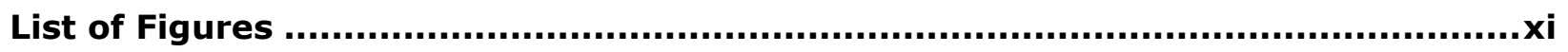

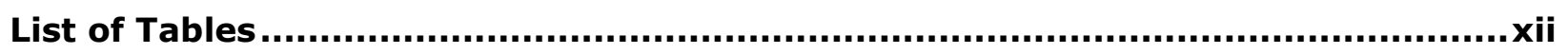

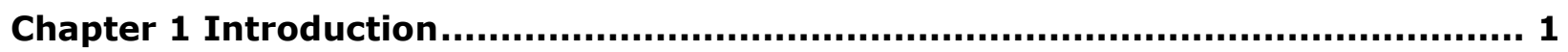

Chapter 2 Geometric Characteristics of Bus Bays ......................................... 3

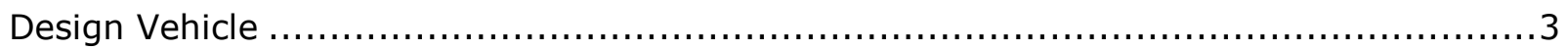

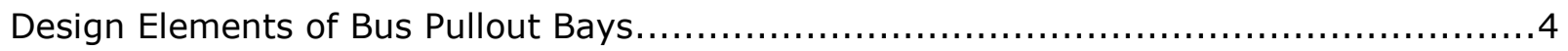

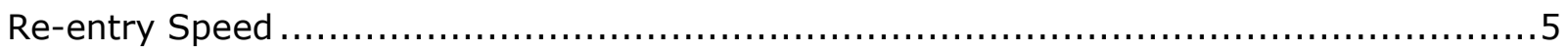



Chapter 3 Recommended Signage and Study Sites..................................... 8

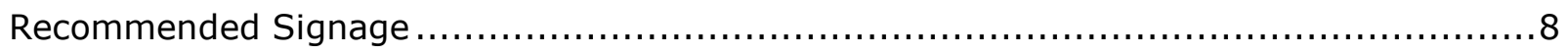

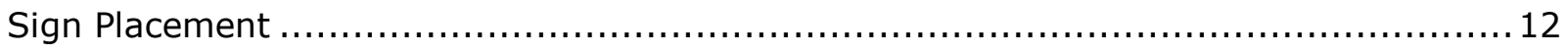

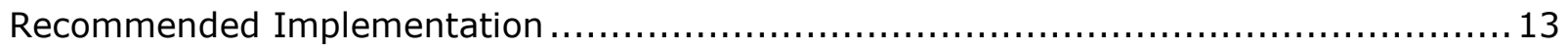



Study Sites in Hillsborough County ................................................. 15

Study Sites in Lee County.......................................................... 18

Chapter 4 Data Collection and Analysis ................................................... 20

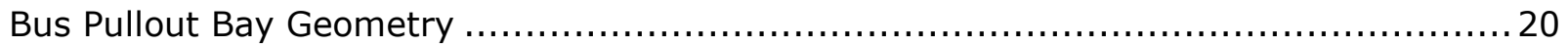

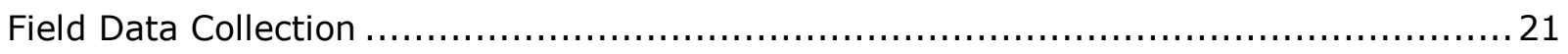

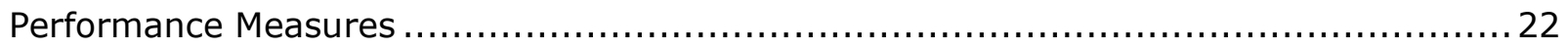

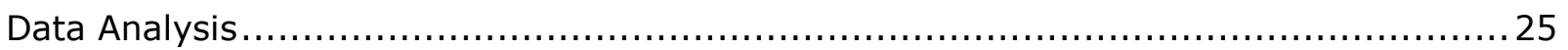

Chapter 5 Conclusions and Recommendations ............................................ 27

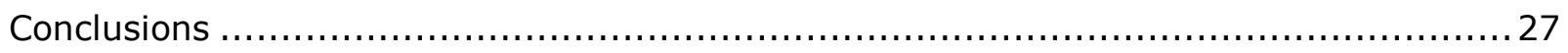

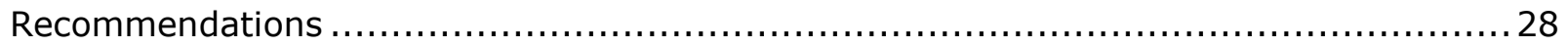






\section{List of Figures}

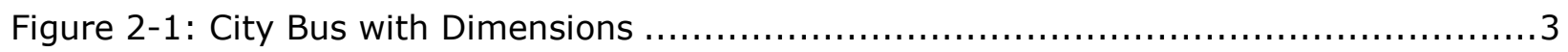



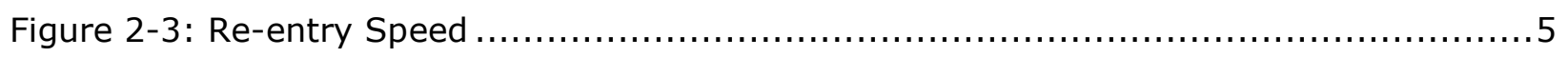

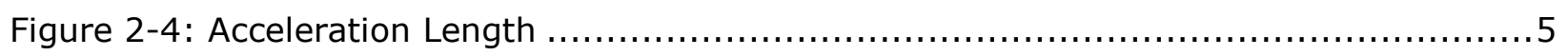

Figure 2-5: Screenshot of the Re-entry Speed Calculator Spreadsheet .....................6

Figure 2-6: Re-entry Speed with Respect to Bus Acceleration for Bus Pullout Bay; Critical

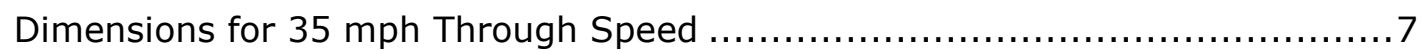

Figure 3-1: Recommended Yield Lines Implementation in the MUTCD $\ldots \ldots \ldots \ldots \ldots \ldots \ldots \ldots \ldots$

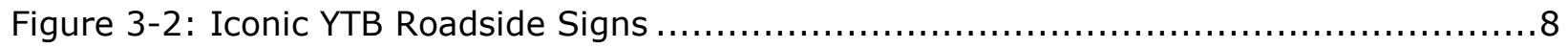



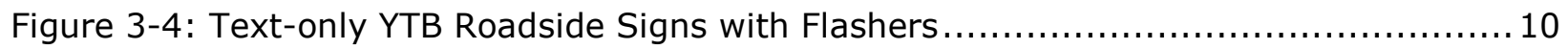

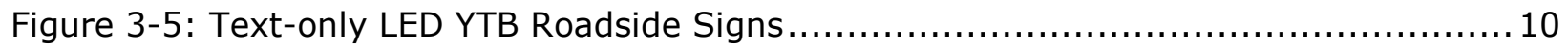



Figure 3-7: Sign Placement Guidelines from MUTCD Table 2C-4 ....................... 12

Figure 3-8: Operation of the Advanced YTB Sign .......................................... 14

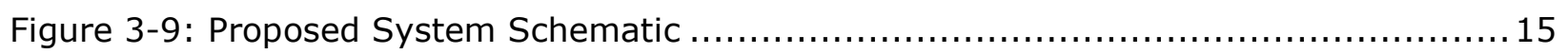

Figure 3-10: Bus Pullout Bay on Nebraska Ave and McBerry St ........................ 16

Figure 3-11: Bus Pullout Bay on Dale Mabry Hwy at Britton Plaza......................... 17

Figure 3-12: Bus Pullout Bay on MLK Blvd at Riga Blvd ................................. 18

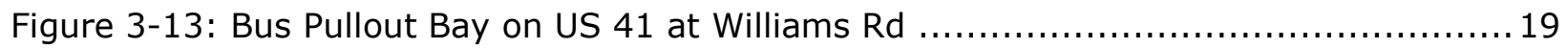



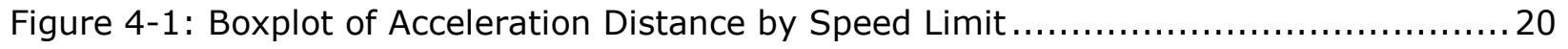

Figure 4-2: Bus Pullout Bay Design Performance Scenarios............................. 21

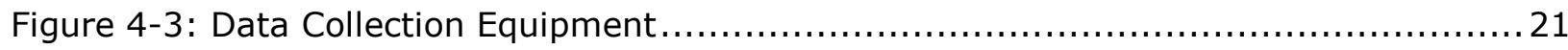

Figure 4-4: Example of Merging Maneuver Ending in Gap and Re-entry Time................23



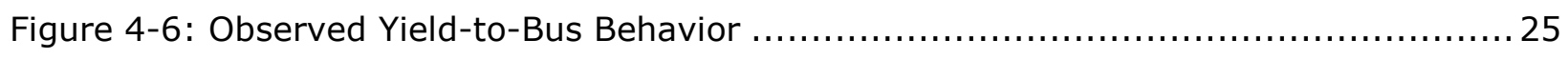

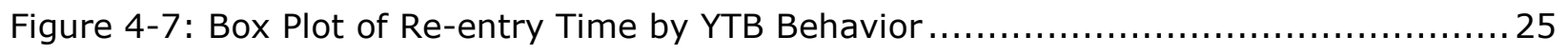

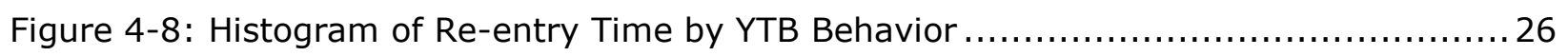




\section{List of Tables}

Table 2-1: Design Vehicles for Geometric Design [3] ....................................

Table 2-2: Critical Dimensions for Bus Pullout Bays Design Elements .......................4

Table 4-1: Traffic Conflict Diagrams for Safety Evaluation ................................ 24 


\section{Chapter 1 Introduction}

A bus pullout bay is a special geometric roadway feature that allows transit buses to stop outside the travel lanes. It facilitates the traffic flow of vehicles on the road while patrons board and alight the stopped bus. At the end of the boarding/alighting operations, the transit bus leaving a bus pullout bay must properly signal and merge back into traffic when it is safe. As transit ridership increases, stopping and merging maneuvers are performed more frequently, thus increasing the interaction between transit buses and the surrounding traffic. Some counties in Florida, such as Lee and Hillsborough, have included bus pullout bays as a design consideration for roadway improvement projects, especially in multimodal districts. There have been several studies in the literature dealing with the location and type of bus stop stops (e.g., near side, far side) from the motorists' viewpoint. However, few quantitative studies have been performed on the operational and safety aspects of bus pullout bays from the transit perspective.

When merging back into traffic, the vehicles on the road may safely yield to the bus entering the flow of traffic. In Florida, such behavior is promoted and enforced by the yieldto-bus (YTB) law. Florida implemented yield-to-bus (YTB) language in their statutes to enhance the safety of bus operations. To promote compliance with the YTB requirements in the statutes, the Florida Department of Transportation (FDOT) has taken a leading role, exploring several treatments for YTB programs, including geometric design. The Accessing Transit Handbook [1] provides guidelines for the design of bus pullout bays for through speeds varying from 25 to $60 \mathrm{mph}$. In addition, some districts have established their own guidelines based on national geometric design standards. Such guidance is based on ideal conditions and should be followed whenever possible. However, in urbanized environments, right-of-way is limited, causing variations in bus pullout bay designs.

The number of lanes and geometric characteristics play an important role in the safety and operational effectiveness of bus pullout bays. They can influence whether an approaching vehicle can safely change lanes to avoid the decelerating bus moving into the bus pullout bay or the bus emerging from the pullout bay in the acceleration lane. In general, the bus should have enough taper acceleration distance to be able to reach a certain speed, usually expressed as a percentage of the through traffic speed.

To assist FDOT on its YTB initiatives, the National Center for Transit Research (NCTR) at the Center for Urban Transportation Research (CUTR) has actively focused on the design of a series of roadside treatments to promote the YTB law. To facilitate compliance with Florida's Yield-to-Bus (YTB) law, this project focuses on the following objectives:

- Identify the critical design features and prevailing conditions affecting the safety of the merging maneuvers of buses entering traffic from bus pullout bays.

- Design a set of roadside treatments or traffic control devices to promote YTB behavior at bus pullout bays. 
- Provide recommendations for implementation and evaluation of YTB traffic control devices on the State Highway System.

To accomplish these goals, a review of the main design elements in the Manual of Uniform Traffic Control Devices, (MUTCD) [2] was performed. Based on the review of the MUTCD a series of preliminary designs were created. The list of designs was reduced based on input from a project panel composed of FDOT project managers and State and District Traffic Operations Engineers. Also, a review of the geometric design elements for bus bays was performed, based on A Policy on Geometric Design of Highway and Streets [3], the Accessing Transit Handbook and Transit Cooperative Research Program (TCRP) Report 19 [4]. Based on the geometric design elements, a spreadsheet (Bus Bay Evaluator, BBE) was created to evaluate the performance of a bus pullout bay for merging operations. Using the bus pullout bays evaluator spreadsheet, a sample of bus pullout bays in different counties in Florida was evaluated. In addition, this project also studied transit crashes and produced a descriptive analysis of the crash trends in Florida.

This study focused on the design elements affecting the merging speed in bus pullout bays and traffic control treatments to promote the YTB law. It provided practitioners with a tool to evaluate the performance of a bus pullout bay. Recommendations for new bus bay designs were also provided. 


\section{Chapter 2 \\ Geometric Characteristics of Bus Bays}

\section{Design Vehicle}

The first element to be considered in the geometric design of a bus bay is the design vehicle. The AASHTO green book [3] is generally used to define design vehicles. In the case of buses a list of design vehicles is presented in Table 2-1 (all dimensions in feet).

Table 2-1: Design Vehicles for Geometric Design [3]

\begin{tabular}{|l|c|c|c|c|c|c|c|c|c|c|}
\cline { 2 - 11 } \multicolumn{1}{c|}{} & Symbol & Height & Width & Length & Front & Rear & WB $_{1}$ & WB $_{2}$ & S & T \\
\hline Intercity Bus & Bus-40 & 12.0 & 8.5 & 40.5 & 6.3 & $9.0^{\mathrm{a}}$ & 25.3 & & & \\
\hline & Bus-45 & 12.0 & 8.5 & 45.5 & 6.2 & $9.0^{\mathrm{a}}$ & 28.5 & & & \\
\hline $\begin{array}{l}\text { City Transit } \\
\text { Bus }\end{array}$ & CITY-BUS & 10.5 & 8.5 & 40.0 & 7.0 & 8.0 & 25.0 & & & \\
\hline $\begin{array}{l}\text { Conventional } \\
\text { School Bus }\end{array}$ & S-BUS 36 & 10.5 & 8.0 & 35.8 & 2.5 & 12.0 & 21.3 & & & \\
\hline $\begin{array}{l}\text { Large School } \\
\text { Bus }\end{array}$ & S-BUS-40 & 10.5 & 8.0 & 40.0 & 7.0 & 13.0 & 20.0 & & & \\
\hline $\begin{array}{l}\text { Articulated } \\
\text { Bus }\end{array}$ & A-BUS & 11 & 8.5 & 60.0 & 8.6 & 10.0 & 22.0 & 19.4 & $6.2^{\mathrm{b}}$ & $13.2^{\mathrm{b}}$ \\
\hline
\end{tabular}

a:This is the length of the overhang from the back axle of the tandem axle assembly

b: Combined dimension is $19.4 \mathrm{ft}$ and articulating section is $4.0 \mathrm{ft}$ wide

The design vehicle for most transit applications is the city bus presented in Figure 2-1. It can be observed that the total length of the bus ( $40 \mathrm{ft}$ ) comprises the front overhang (length from the front bumper to the front wheel axle, $7 \mathrm{ft}$ ), the length between axles (25 $\mathrm{ft}$ ) and the rear overhang (length from rear wheel axle to rear bumper, $8 \mathrm{ft}$ ).

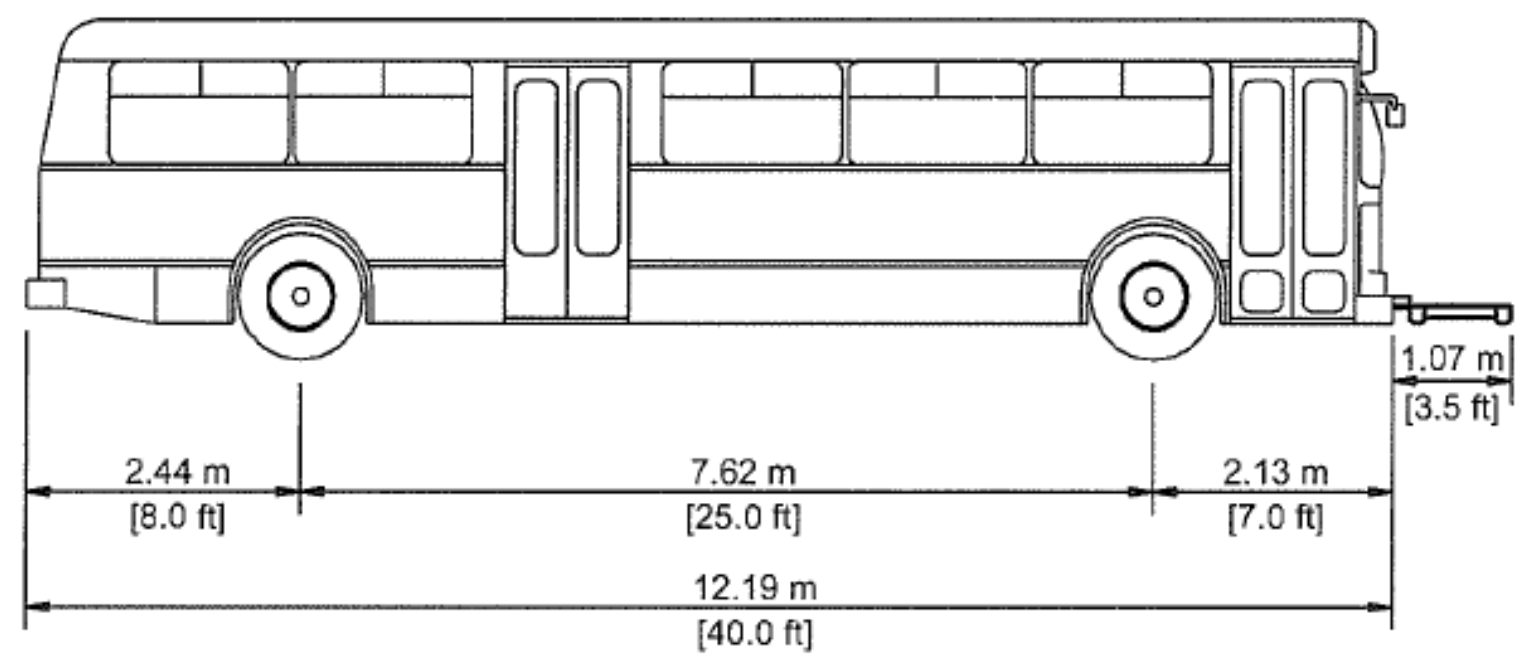

Figure 2-1: City Bus with Dimensions 


\section{Design Elements of Bus Pullout Bays}

In this section, the design elements of a bus bay are described. The discussion is focused on the merging operation of the bus bay. The design features considered were adopted from the Accessing Traffic Handbook [1].

A bus pullout bay typically consists on an entrance taper, deceleration area, and stopping area for entering maneuvers. For merging back into traffic, the design elements are acceleration area, and the exit taper. Such design elements are presented in Figure 2-2.

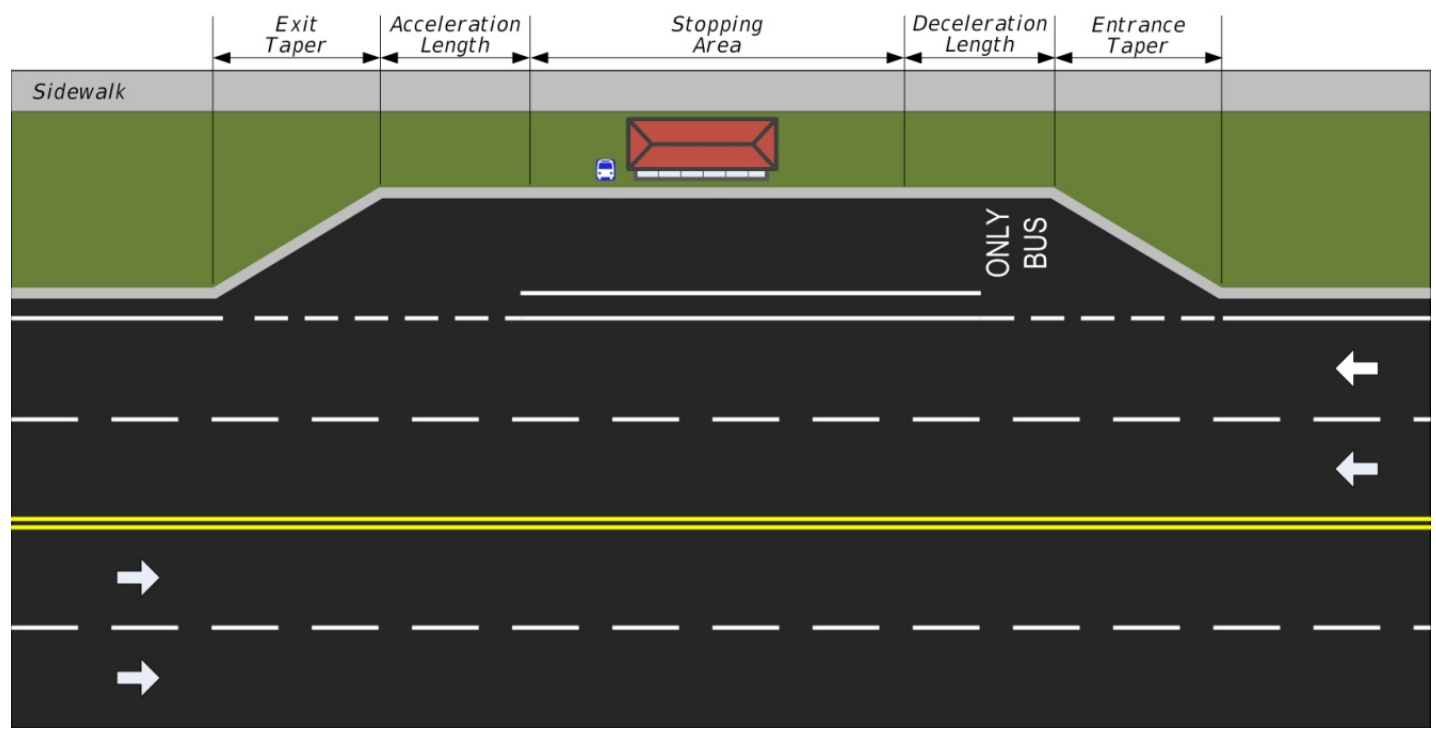

Figure 2-2: Design Elements of Bus Pullout Bays

The dimensions of the design elements depend on the speed of the transportation facility. General design guidelines are presented in the Accessing Traffic Handbook [1]. The critical dimensions for bus pullout bays are presented in Table 2-2.

Table 2-2: Critical Dimensions for Bus Pullout Bays Design Elements

\begin{tabular}{|c|c|c|c|c|}
\hline $\begin{array}{c}\text { Through } \\
\text { Speed }(\mathrm{mph})\end{array}$ & $\begin{array}{c}\text { Entering } \\
\text { Speed }(\mathrm{mph})\end{array}$ & $\begin{array}{c}\text { Length of } \\
\text { Acceleration Lane }(\mathrm{ft})\end{array}$ & $\begin{array}{c}\text { Length of } \\
\text { Deceleration Lane }(\mathrm{ft})\end{array}$ & $\begin{array}{c}\text { Length of } \\
\text { Taper }(\mathrm{ft})\end{array}$ \\
\hline $\mathbf{2 5}$ or less & 15 or less & $\begin{array}{c}60 \text { (desired) } \\
80 \text { (minimum) }\end{array}$ & $\begin{array}{c}80 \text { (desired) } \\
60 \text { (minimum) }\end{array}$ & - \\
\hline $\mathbf{3 5}$ & 25 & 250 & 184 & 170 \\
\hline $\mathbf{4 0}$ & 30 & 400 & 265 & 190 \\
\hline $\mathbf{4 5}$ & 35 & 700 & 360 & 210 \\
\hline $\mathbf{5 0}$ & 40 & 975 & 470 & 230 \\
\hline $\mathbf{5 5}$ & 45 & 1,400 & 595 & 250 \\
\hline $\mathbf{6 0}$ & 50 & 1,900 & 735 & 270 \\
\hline
\end{tabular}

The critical dimensions for bus pullout bays presented in Table 2-2 allow the bus to achieve a merging or entering speed that is $10 \mathrm{mph}$ below the through speed for the facility. In urbanized environments, space availability restrictions limit the application of the bus 
pullout bay critical dimensions. In this work, the re-entry speed will be evaluated as a measure of the performance of the bus pullout bay design.

\section{Re-entry Speed}

The re-entry speed for the purpose of analysis is defined as the speed reached when the rear bumper of the bus reaches the end of the exit taper of the bus pullout bay, as presented in Figure 2-3.

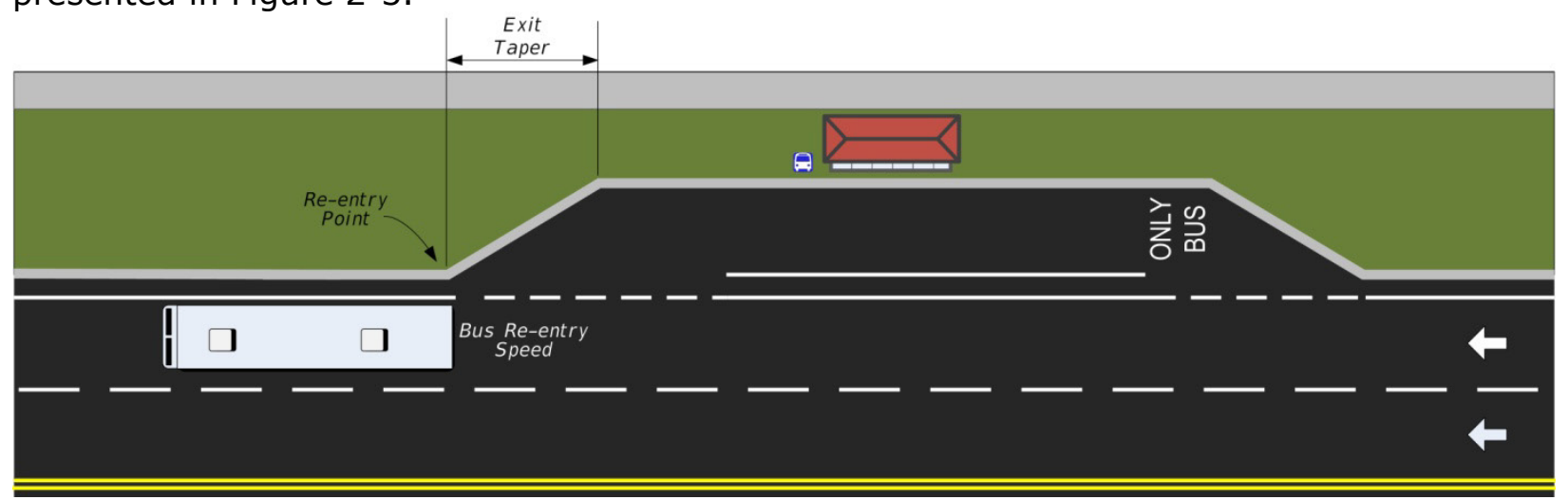

Figure 2-3: Re-entry Speed

The re-entry speed of a bus depends on several factors such as bus size, acceleration length, and driving behavior. For a given bus pullout bay geometry, the re-entry speed can be calculated using the bus acceleration, through the following formulas from the laws of linear motion [3].

$$
\begin{gathered}
V_{f}^{2}=V_{o}^{2}+2 a d \\
V_{f}=\sqrt{V_{o}^{2}+2 a d}
\end{gathered}
$$

Where $V_{f}$ is the merging speed (fps), $V_{o}$ is the initial speed (fps), a is the acceleration rate (fps2) and $\mathrm{d}$ is the acceleration distance ( $\mathrm{ft}$ ). The acceleration distance is the trajectory of the front bumper of the bus. The acceleration distance is the sum of the remaining length of the stopping area, the acceleration length, exit taper, and bus length (minus front overhang if applicable).

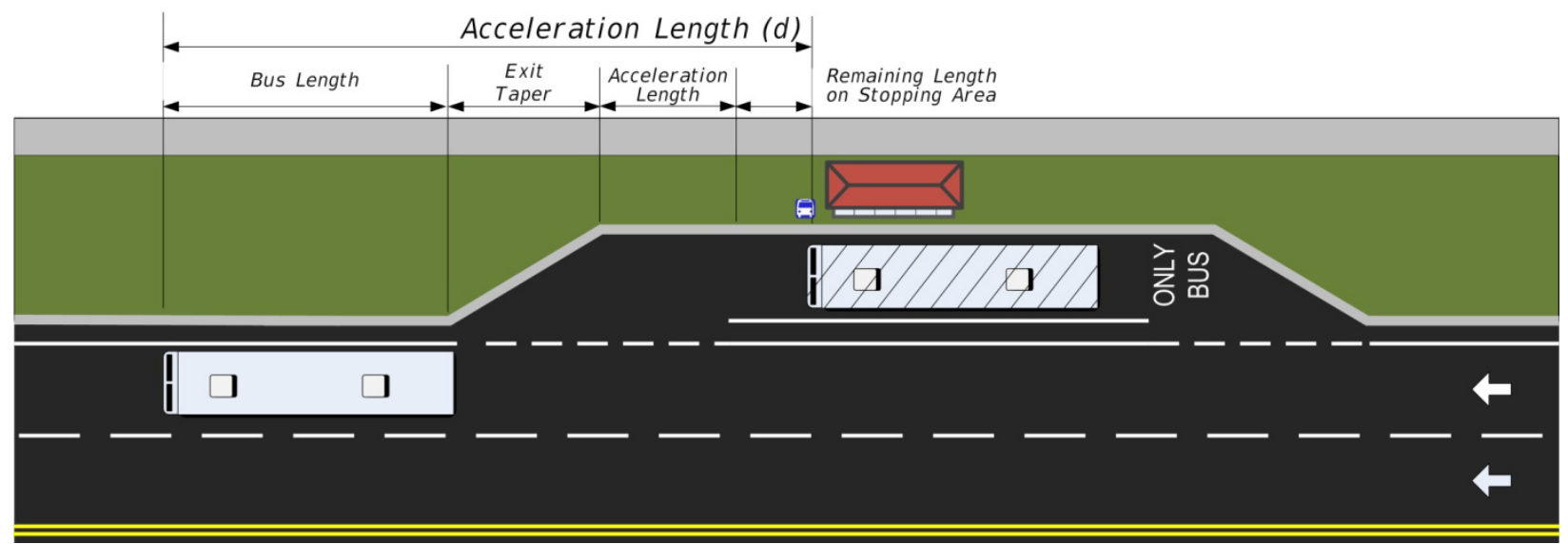

Figure 2-4: Acceleration Length 
Acceleration rate may vary depending on engine power and human factors. TCRP Report 100: Transit Capacity and Quality of Service [5] recommends an average acceleration of 4 $\mathrm{fps}^{2}$ [3]. The re-entry speed given by Equation Equation $\mathbf{2 - 1}$ is expressed in $\mathrm{fps}$ and is converted to mph by using the factor $F=0.6818$.

\section{Re-entry Speed Calculator Spreadsheet}

A spreadsheet application to calculate the re-entry speed of a bus bay was developed by considering the previously defined design elements. The spreadsheet simplifies the input process by summarizing all the critical bus pullout bay design parameters in the acceleration distance field. As an example, the second row of Table 2-2 with a through speed of $35 \mathrm{mph}$ was input in the spreadsheet. The acceleration length is $250 \mathrm{ft}$ and the acceleration taper is $170 \mathrm{ft}$. The total acceleration distance is $462 \mathrm{ft}$. using $2.85 \mathrm{fps}^{2}$ as the value of acceleration and a re-entry speed of $35 \mathrm{mph}$, reaching 100 percent of the through speed. The spreadsheet also provides scaled drawings of the bus bay, showing the bus stop and the reentry point.

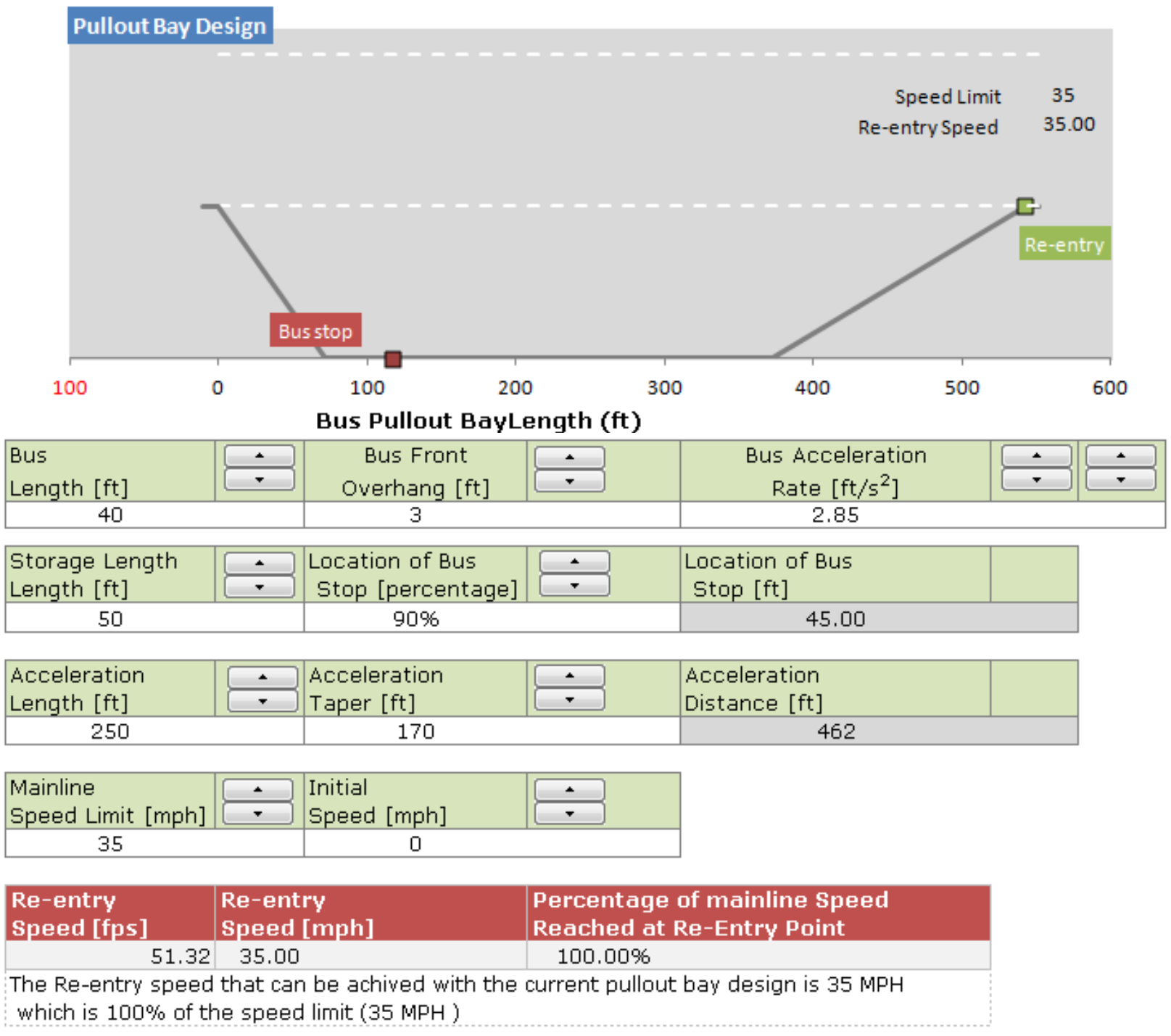

Figure 2-5: Screenshot of the Re-entry Speed Calculator Spreadsheet 
The re-entry speed calculator was used to determine the performance of the study site. This performance is related to the bus acceleration and it varies based on a number of variables, including human factors. To manage those situations, a performance measure range within a moderate acceleration ranges will be provided. For the $35 \mathrm{mph}$ case, the re-entry speed, as a function of the different acceleration values, is presented in Figure 2-6.

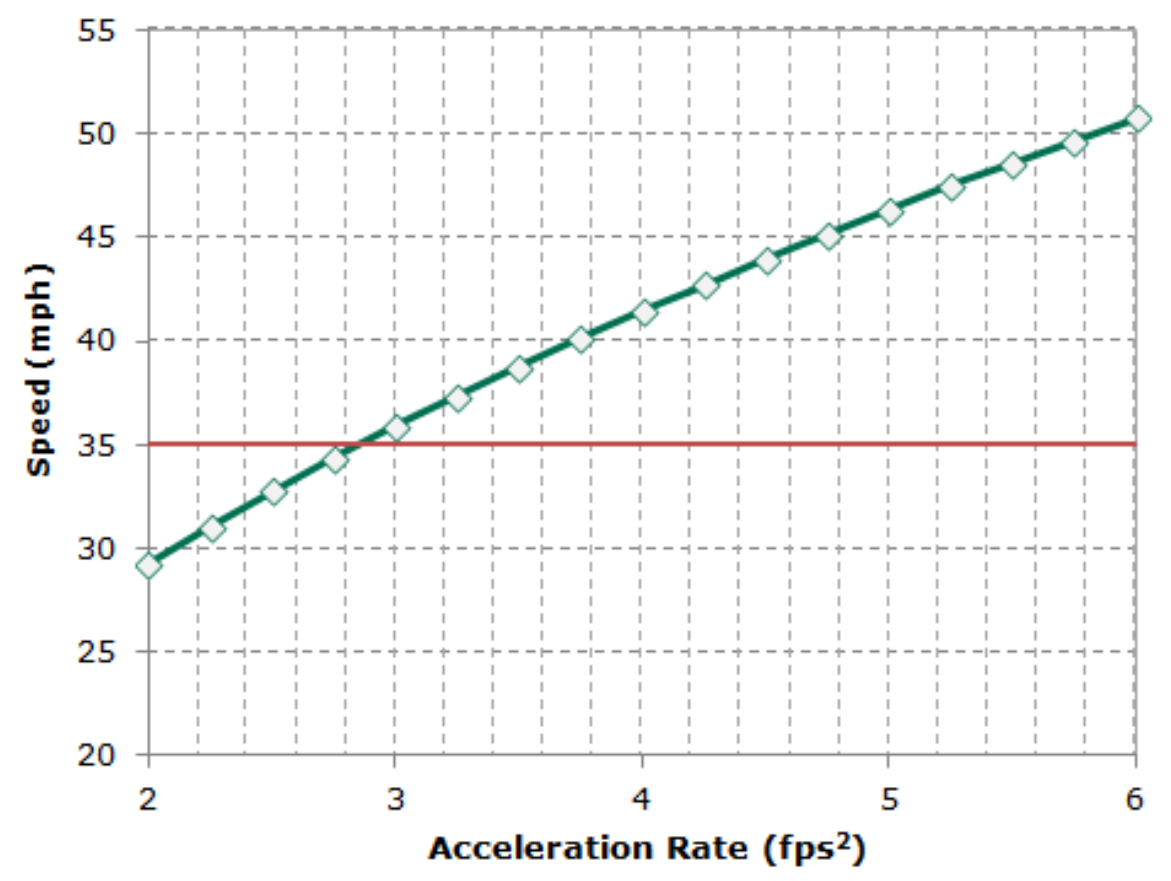

Figure 2-6: Re-entry Speed with Respect to Bus Acceleration for Bus Pullout Bay; Critical Dimensions for 35 mph Through Speed

In Figure 2-6, it can be observed that for the given acceleration distance the bus can accelerate at a moderate acceleration rate of $2.84 \mathrm{fps}^{2}$, reaching the full speed for the transportation facility. In urbanized areas with constrained right-of-way the acceleration distance may be reduced and more bus acceleration may be required. It is important to note that acceleration lanes do not need to reach full speed for the through facility. A value of 85 percent of the through speed is usually recommended as the target speed for acceleration lanes. In urbanized environments for large vehicles such as transit buses a lower value is generally allowable. 


\section{Chapter 3 \\ Recommended Signage and Study Sites}

\section{Recommended Signage}

Promoting yield-to-bus (YTB) behavior may require special signage at certain locations. YTB signage could be in-bus signage or road signage. In-bus signage can be passive, such as the YTB decal or active as in the case of flashing Light Emitting Diode (LED) signs. A detailed analysis of the implementation and effectiveness of the assessment of in-bus active signage can be found in reference [6].

Road signage can be in the form of pavement markings or roadside signs. Although the pavement marking signs may be used to indicate a yield action, its implementation to bus stops is not defined in the MUTCD. In addition, for multi-lane roads, the treatment may only apply to the lane adjacent to the bus pullout bay, which may lead to confusion. The recommended implementation of yield lines by the MUTCD is presented in Figure 3-1. It can be observed (b) that the treatment is applied uniformly to the direction of travel.

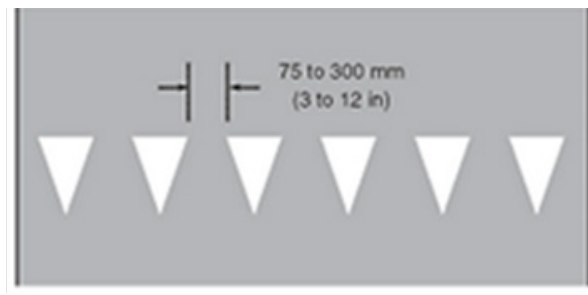

a. Yield line



b. Yield line on a 4-lane road

Figure 3-1: Recommended Yield Lines Implementation in the MUTCD

There are several alternative designs for roadside signs. For iconic designs, human factors such as interpretation are involved, which require major testing and approval. Figure 3-2 presents alternative designs for iconic roadside YTB signs.



\section{STATE LAW}



BUS

ENTERING

TRAFFIC

Figure 3-2: Iconic YTB Roadside Signs 
In Figure 3-2, it can be observed that the sign on the left contains two major iconic components, the universal yield sign (inverted triangle) and a bus silhouette. The sign on the right in Figure 3-2 contains a combination of the universal yield sign and text.

Text-only signs can be implemented by state and local agencies as long as regulations on the size of the letters, for legibility, are followed. In general, YTB signs can be installed at designated bus pullout bays since these signs support an existing regulation (FL Statute 316.0815). YTB roadside signs may not be installed at regular bus stops or other locations not defined in the Florida Statutes. Some iconic signs are being proposed for consideration for future implementation and testing. Candidate text-only YTB roadside signs are presented in Figure 3-3. Word messages in the legend of regulatory signs must be in upper-case letters, at least eight inches high for roadways, with operating speeds of $35 \mathrm{mph}$ or less. Larger lettering must be used for roadways with higher speeds.

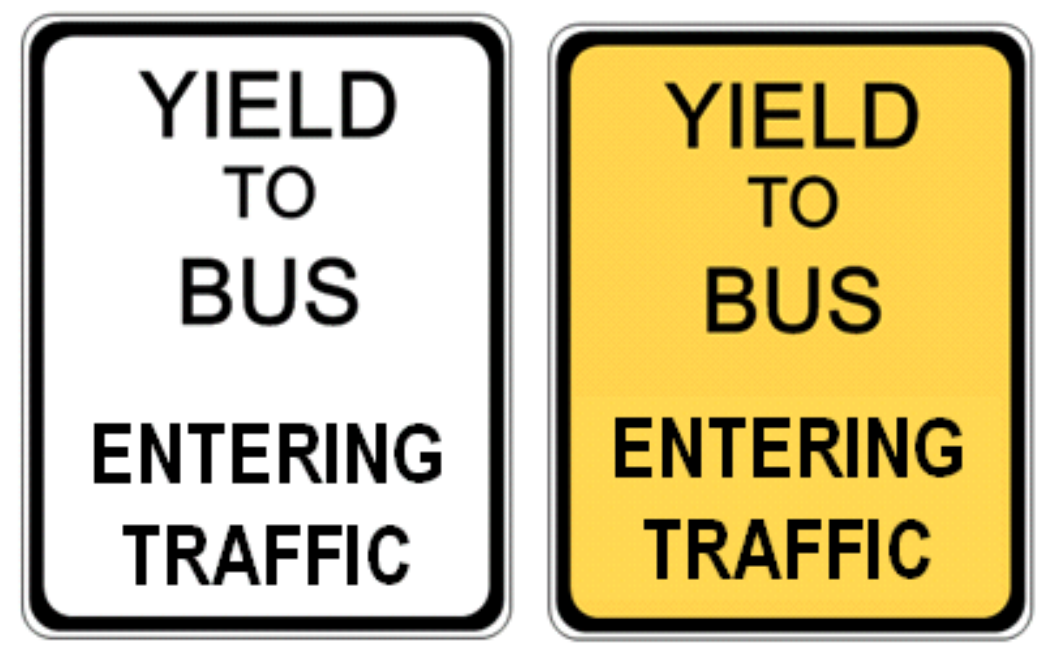

Figure 3-3: Text-only YTB Roadside Signs

Roadside YTB signs can be considered as a passive YTB treatment. A more active treatment consists of adding flashers to the sign. The flasher can be activated by the bus with an onboard device, radio-frequency tag, or by a detector at the bus stop. YTB roadside signs with flashers may have one flasher on top of the sign or two flashers alternating above and below the sign to direct more attention on the sign message. Figure 3-4 presents alternative designs and wording for the YTB roadside signs with flashers. Alternative wording for the YTB roadside sign with flashers included a small portion of the sign showing the text, "State Law" and other main text, including:

- Yield to bus

- Yield to bus when flashing

- Yield to bus when entering traffic

- Yield to bus merging into traffic

- Yield to bus leaving pullout bay

There are several key aspects to take into consideration before selecting the final wording for the text-only signs with flashers. Adding more messages such as, "when flashing" may have undesired interpretations. For example, some drivers may interpret that they need to yield only when flashers are present. This diverts from the YTB law since traffic must yield to the bus in all designated bus pullout bays, irrespective of the presence of signs or flashers. The message, "entering traffic" seems to be easier to interpret and more general. 
It is recommended that the alternative wordings are subject to further validation through a survey instrument.
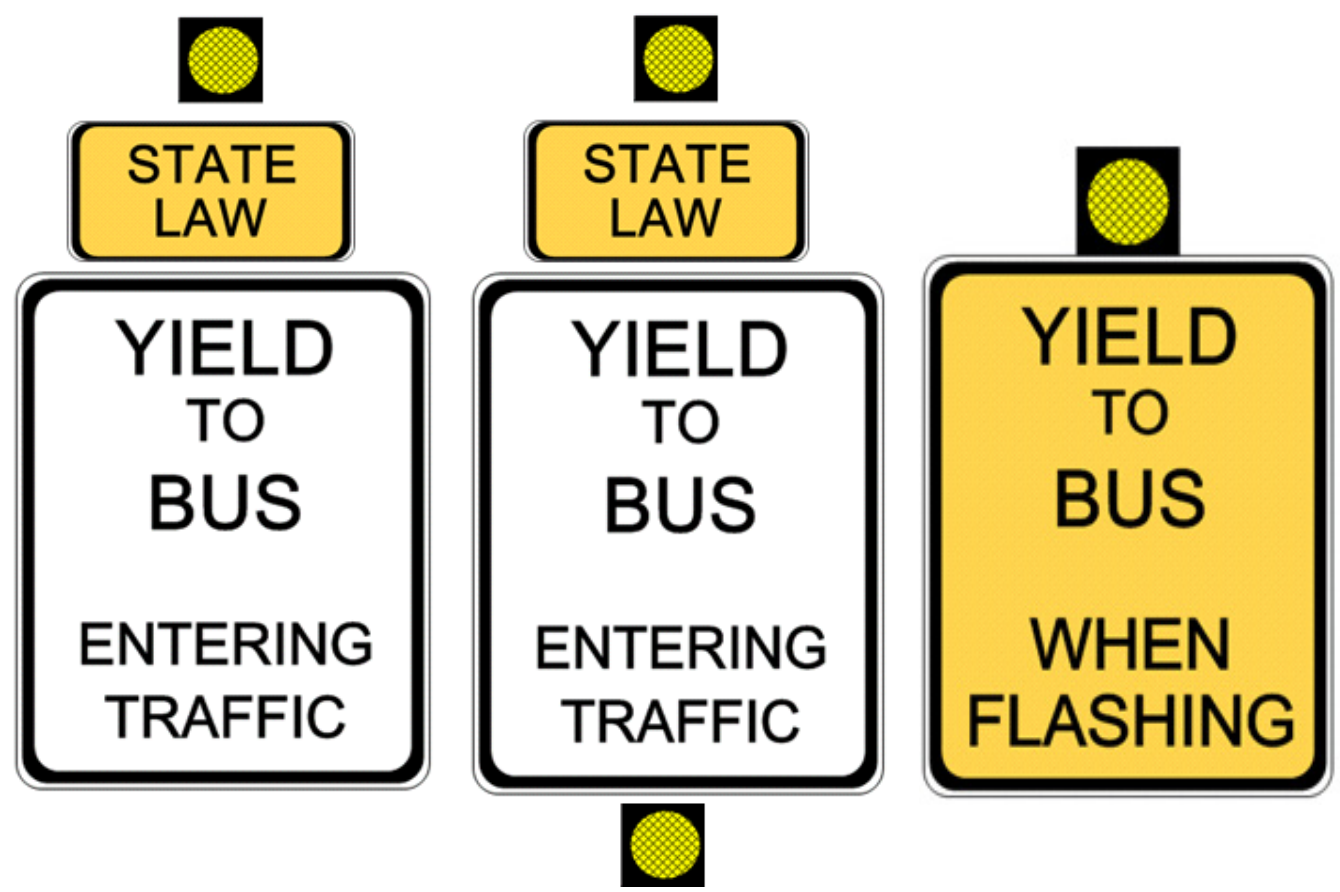

Figure 3-4: Text-only YTB Roadside Signs with Flashers

A more advanced YTB sign consists of replacing the text portion of the signs with an LED message board. The LED message board may have any of the wordings previously defined and it can be changed or updated easily. Another advantage of the LED message board is that the text will be visible only when the bus is merging back into traffic. An additional feature includes flashing the LED display to get more attention. Such aspects can be subject to human factor research to determine the effectiveness of the sign design. Figure 3-5 presents examples of LED YTB roadside signs.

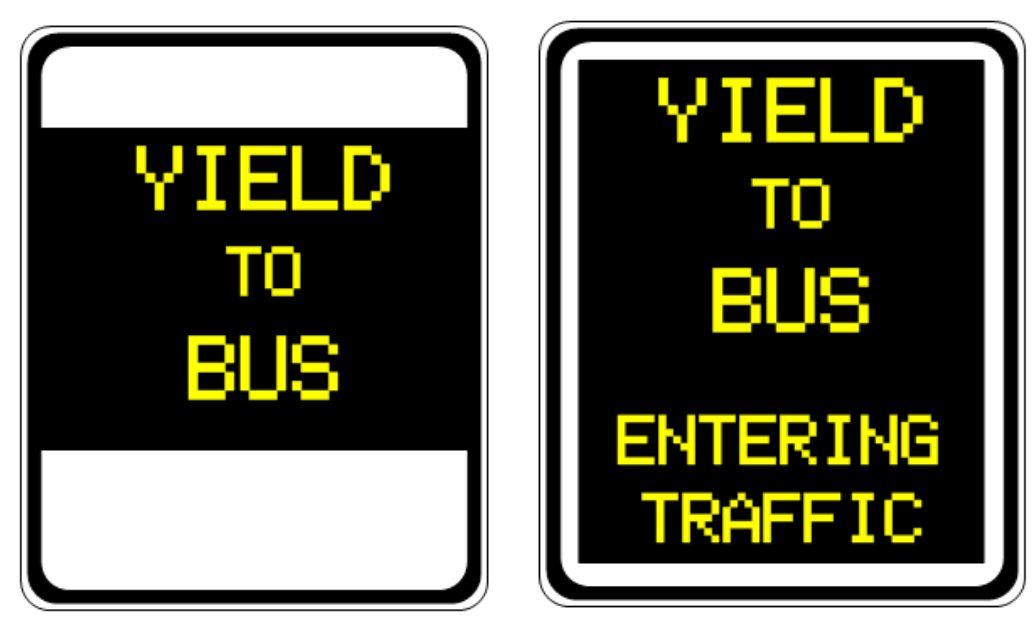

Figure 3-5: Text-only LED YTB Roadside Signs 
Based on the preliminary discussion and other requirements, such as sign cost and permissions, the roadside sign designs presented in Figure 3-6 were selected as the sign candidates.

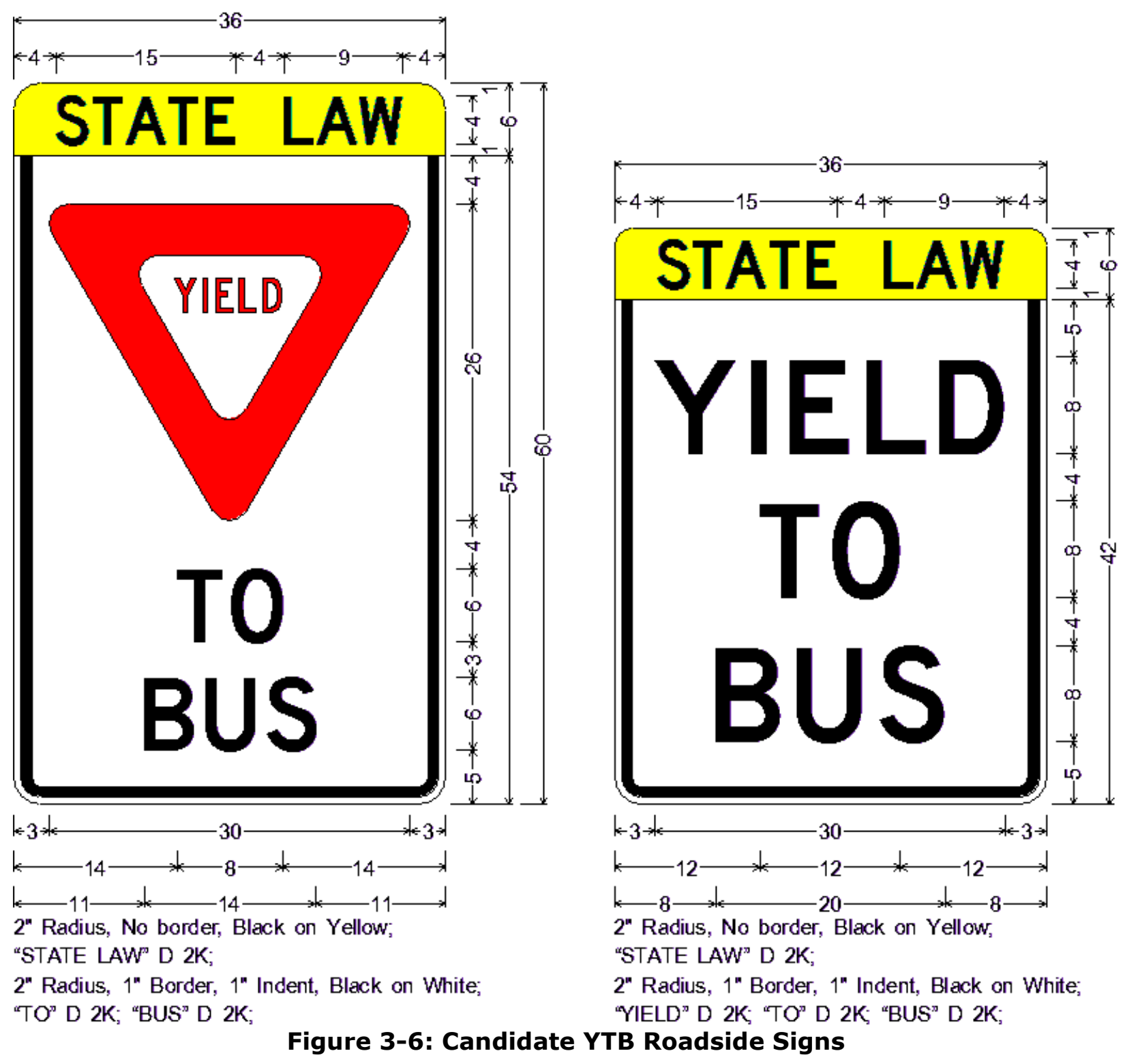

Figure 3-6 presents two designs; the sign on the right contains the text "Yield to Bus". This was set in conjunction with an advisory group, comprising of by State and Districts Traffic Operations Engineers (PTOEs) and FDOT sign specialists. The sign on the left presents the yield symbol (inverted triangle) instead of the respective word. Either one of the candidate signs could be combined with flashers to provide a more active role in promoting yield-tobus behavior. However, the text-only sign is recommended for implementation and testing since it does not contain symbols that require driver's interpretation.

In addition to sign specifications, for testing purposes, it is recommended that the YTB signs are not installed in close proximity with other regulatory signs such as speed limits or stop signs. If the sign is to include flashers, then it should be installed on locations distant from 
traffic lights, emergency beacons, school zone flashers etc. to avoid information overload for the general public.

\section{Sign Placement}

YTB sign placement should meet the guidelines contained in the MUTCD [2]. The YTB sign as presented in Figure 3-6 it was assumed as a tree-word sign for interpretation purposes. The white background implies that is a regulatory signs and it is therefore enforcing an existing law. The sign legend height is 8 inches, providing good legibility. Sign placement can be determined based on section 2C.05 of MUTCD "Placement of Warning Signs", which recommends $125 \mathrm{ft}$ for a speed reduction from $45 \mathrm{mph}$ (posted speed) to $10 \mathrm{mph}$. Another plausible scenario is a reduction to $20 \mathrm{mph}$ using $100 \mathrm{ft}$ for advance sign placement for a 45 mph speed limit. Figure 3-7 presents Table 2C-4 of MUTCD that contains guidelines for advance sign placement. For the case of YTB sign a yield speed of $20 \mathrm{MPH}$ is recommended. In such case the sign placement is at $100 \mathrm{ft}$ from the beginning of the bus bay when the posted speed limit is $45 \mathrm{mph}$ or less.

\begin{tabular}{|c|c|c|c|c|c|c|c|c|c|}
\hline \multirow{3}{*}{$\begin{array}{l}\text { Posted } \\
\text { or 85th- } \\
\text { Percentile } \\
\text { Speed }\end{array}$} & \multicolumn{9}{|c|}{ Advance Placement Distance $^{1}$} \\
\hline & \multirow{2}{*}{$\begin{array}{c}\text { Condition A: } \\
\text { Speed reduction } \\
\text { and lane } \\
\text { changing in } \\
\text { heavy traffic } \\
\end{array}$} & \multicolumn{8}{|c|}{ Condition B: Deceleration to the listed advisory speed $(\mathrm{mph})$ for the condition } \\
\hline & & $0^{3}$ & $10^{4}$ & $20^{4}$ & $30^{4}$ & $40^{4}$ & $50^{4}$ & $60^{4}$ & $70^{4}$ \\
\hline $20 \mathrm{mph}$ & $225 \mathrm{ft}$ & $100 \mathrm{ft}^{6}$ & N/A $A^{5}$ & - & - & - & - & - & - \\
\hline $25 \mathrm{mph}$ & $325 \mathrm{ft}$ & $100 \mathrm{ft}^{6}$ & $\mathrm{~N} / \mathrm{A}^{5}$ & $N / A^{5}$ & - & - & - & - & - \\
\hline $30 \mathrm{mph}$ & $460 \mathrm{ft}$ & $100 \mathrm{ft}^{6}$ & $N / A^{5}$ & $N / A^{5}$ & - & - & - & - & - \\
\hline $35 \mathrm{mph}$ & $565 \mathrm{ft}$ & $100 \mathrm{ft}^{6}$ & $N / A^{5}$ & $N / A^{5}$ & $N / A^{5}$ & - & - & - & - \\
\hline $40 \mathrm{mph}$ & $670 \mathrm{ft}$ & $125 \mathrm{ft}$ & $100 \mathrm{ft}^{6}$ & $100 \mathrm{ft}^{6}$ & $N / A^{5}$ & - & - & - & - \\
\hline $45 \mathrm{mph}$ & $775 \mathrm{ft}$ & $175 \mathrm{ft}$ & $125 \mathrm{ft}$ & $100 \mathrm{ft}^{6}$ & $100 \mathrm{ft}^{6}$ & $\mathrm{~N} / \mathrm{A}^{5}$ & - & - & - \\
\hline $50 \mathrm{mph}$ & $885 \mathrm{ft}$ & $250 \mathrm{ft}$ & $200 \mathrm{ft}$ & $175 \mathrm{ft}$ & $125 \mathrm{ft}$ & $100 \mathrm{ft}^{6}$ & - & - & - \\
\hline $55 \mathrm{mph}$ & $990 \mathrm{ft}$ & $325 \mathrm{ft}$ & $275 \mathrm{ft}$ & $225 \mathrm{ft}$ & $200 \mathrm{ft}$ & $125 \mathrm{ft}$ & $\mathrm{N} / \mathrm{A}^{5}$ & - & - \\
\hline $60 \mathrm{mph}$ & $1,100 \mathrm{ft}$ & $400 \mathrm{ft}$ & $350 \mathrm{ft}$ & $325 \mathrm{ft}$ & $275 \mathrm{ft}$ & $200 \mathrm{ft}$ & $100 \mathrm{ft}^{6}$ & - & - \\
\hline $65 \mathrm{mph}$ & $1,200 \mathrm{ft}$ & $475 \mathrm{ft}$ & $450 \mathrm{ft}$ & $400 \mathrm{ft}$ & $350 \mathrm{ft}$ & $275 \mathrm{ft}$ & $200 \mathrm{ft}$ & $100 \mathrm{ft}^{6}$ & - \\
\hline $70 \mathrm{mph}$ & $1,250 \mathrm{ft}$ & $550 \mathrm{ft}$ & $525 \mathrm{ft}$ & $500 \mathrm{ft}$ & $450 \mathrm{ft}$ & $375 \mathrm{ft}$ & $275 \mathrm{ft}$ & $150 \mathrm{ft}$ & - \\
\hline $75 \mathrm{mph}$ & $1,350 \mathrm{ft}$ & $650 \mathrm{ft}$ & $625 \mathrm{ft}$ & $600 \mathrm{ft}$ & $550 \mathrm{ft}$ & $475 \mathrm{ft}$ & $375 \mathrm{ft}$ & $250 \mathrm{ft}$ & $100 \mathrm{ft}^{6}$ \\
\hline
\end{tabular}

${ }^{1}$ The distances are adjusted for a sign legibility distance of 180 feet for Condition A. The distances for Condition B have been adjusted for a sign legibility distance of $\mathbf{2 5 0}$ feet, which is appropriate for an alignment warning symbol sign. For Conditions A and B, warning signs with less than 6 -inch legend or more than four words, a minimum of 100 feet should be added to the advance placement distance to provide adequate legibility of the warning sign.

${ }^{2}$ Typical conditions are locations where the road user must use extra time to adjust speed and change lanes in heavy traffic because of a complex driving situation. Typical signs are Merge and Right Lane Ends. The distances are determined by providing the driver a PRT of 14.0 to 14.5 seconds for vehicle maneuvers (2005 AASHTO Policy, Exhibit 3-3, Decision Sight Distance, Avoidance Maneuver E) minus the legibility distance of 180 feet for the appropriate sign.

${ }^{3}$ Typical condition is the warning of a potential stop situation. Typical signs are Stop Ahead, Yield Ahead, Signal Ahead, and Intersection Warning signs. The distances are based on the 2005 AASHTO Policy, Exhibit 3-1, Stopping Sight Distance, providing a PRT of 2.5 seconds, a deceleration rate of 11.2 feet/second ${ }^{2}$, minus the sign legibility distance of 180 feet.

${ }^{4}$ Typical conditions are locations where the road user must decrease speed to maneuver through the warned condition. Typical signs are Turn, Curve, Reverse Turn, or Reverse Curve. The distance is determined by providing a 2.5 second PRT, a vehicle deceleration rate of 10 feet/second ${ }^{2}$, minus the sign legibility distance of 250 feet.

${ }^{5}$ No suggested distances are provided for these speeds, as the placement location is dependent on site conditions and other signing. An alignment warning sign may be placed anywhere from the point of curvature up to 100 feet in advance of the curve. However, the alignment warning sign should be installed in advance of the curve and at least 100 feet from any other signs.

${ }^{6}$ The minimum advance placement distance is listed as 100 feet to provide adequate spacing between signs.

Figure 3-7: Sign Placement Guidelines from MUTCD Table 2C-4 


\section{Recommended Implementation}

To manage the problem of yielding to a bus reentering traffic, it is proposed that a system be put into place which detects the presence of a bus ready to merge and then activates a YTB roadside sign with flashers to signalapproaching traffic. This system should be automated and built to detect a city transit bus [3].

This system can be built with commercial off-the-shelf (COTS) products, combined with standard roadway signage, to implement the required functionality. The proposed system uses short range light detection and ranging (LIDAR) devices to detect the presence of a bus, in combination with a microcontroller and short-range transmitter to send the necessary data to activate a solar-powered YTB sign with flashers.

The system would make use of two LIDAR devices, mounted in the bus bay at a height near city bus height $(10.5 \mathrm{ft})$ in order to eliminate false positives. The devices would be mounted and separated by a distance near city bus length $(40.0 \mathrm{ft})$, further eliminating false positives, as well as providing accurate timing for activation of the merging bus warning. The sensors should be mounted at an appropriate distance from the road in order to detect buses when in the bus bay, but not detecting passing buses in the main roadway. This can be accomplished either by placement of the sensors or in microcontroller software by limiting the range of values that trigger a positive result.

Timing and functionality of the system is as follows and illustrated inFigure 3-8. In the operation of the advanced YTB sign, green represents an active component, yellow represents a standby component, and red represents an inactive component. The operation of the advanced YTB signs is as follows:

1. Bus begins pulling into bus bay, activating first LIDAR sensor (Figure 3-8 a)

2. Bus pulls into bus bay and stops in a location activating both LIDAR sensors

3. System is put into standby mode as both sensors recognize the presence of the bus (Figure 3-8b)

4. Bus moves forward in bus bay in an attempt to merge back into traffic

5. As the rear sensor is uncovered, system activates and signals merging sign to begin flashing (Figure 3-8c)

6. System flashes for a designated amount of time after front sensor is uncovered

7. System returns to inactive mode after set time has elapsed

The only requirement for a bus driver would be stopping in a location where both sensors are covered. A margin of error can be provided by reducing the distance between sensors. However, the back sensor must be placed in such a position that, when uncovered to trigger the sign, it gives adequate warning to approaching drivers. Figure 3-9presents the proposed schematic for the field implementation of the advanced YTB sign. 


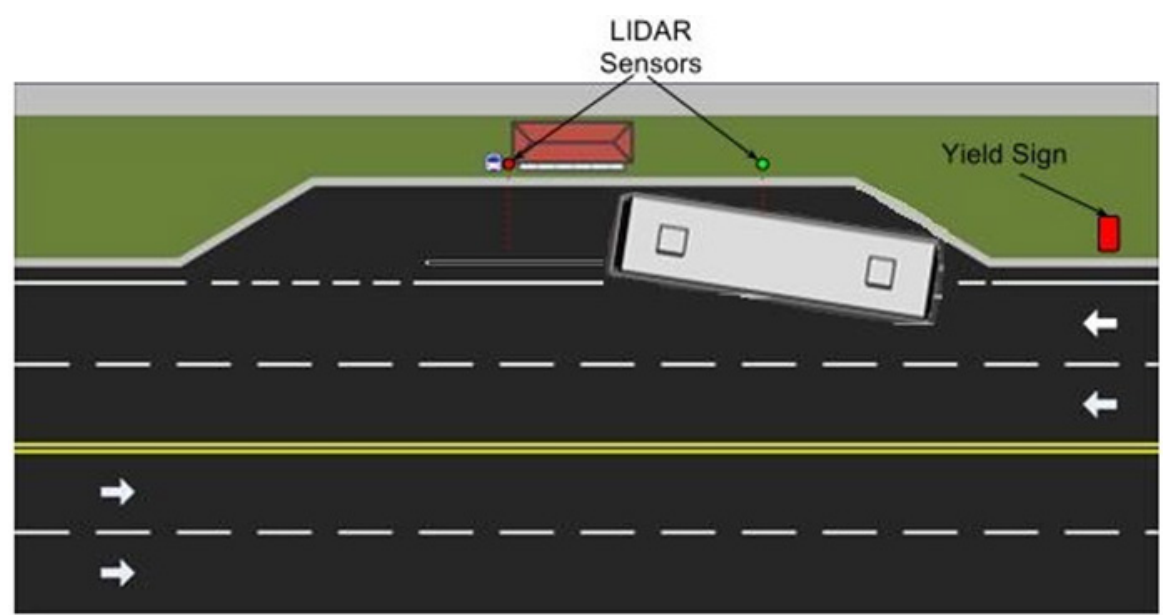

a. Bus arrival, YTB sign inactive, one LIDAR sensor active



b. Bus stopped, YTB sign in standby, both LIDAR sensors active



b. Bus ready, YTB sign active, forward LIDAR sensors active

Figure 3-8: Operation of the Advanced YTB Sign 


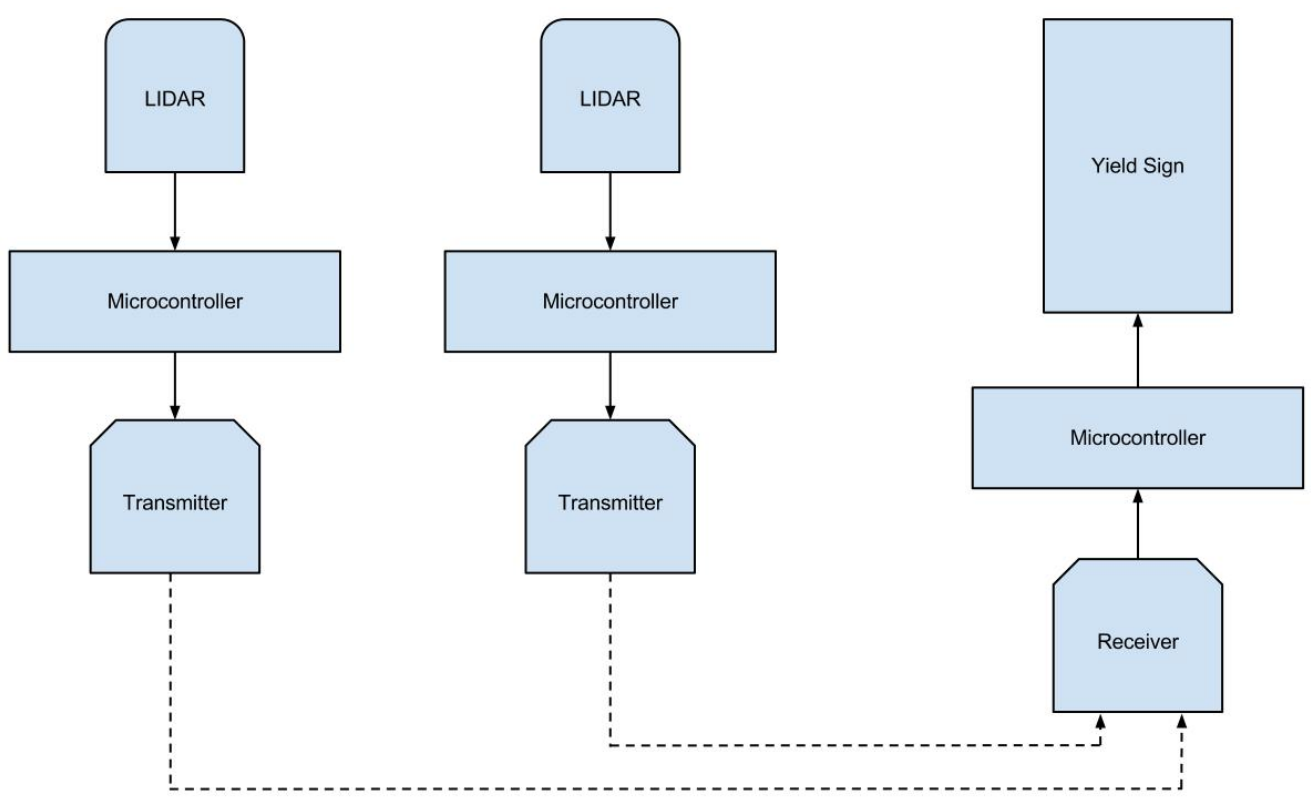

Figure 3-9: Proposed System Schematic

\section{Study Sites}

The study was designed to be applied in Hillsborough and Lee County, initially. The tests will be performed on state roads to facilitate the permissions for sign installation. Sign selection was made by using a combination of GIS information and site visits. GIS layers containing information for bus stops were requested form different agencies. The GIS layer received contained up-to-date information on bus stop amenities and other transit information. One aspect that can be improved is to incorporate traffic safety features as part of the GIS reporting data. For example, the presence of a bus bay, geometry of the bus bay, indicator if the bus stop is on a right-turn lane etc. Such information is useful to perform safety assessment of roadway feature pertaining transit operations.

\section{Study Sites in Hillsborough County}

Nebraska Ave at McBerry St: This bus bay is located in the northbound direction on Nebraska Ave (SR 45). It has different amenities such as shelter, bench, and landing pad. It can be observed that is well delineated as bus-only lane as shown in Figure 3-10. The bus pullout bays are located on a two-lane road which generates conflicts. YTB treatments will have major effects on these types of road as presented in reference [6]. 




Figure 3-10: Bus Pullout Bay on Nebraska Ave and McBerry St

Britton Plaza: This bus pullout bay is located in the northbound direction of Dale Mabry Hwy (SR 600). The closest intersection is W. Euclid Ave at South Dale Mabry Hwy. The bus pullout bay serves as staging area for several bus types as can be observed in Figure 3-11. The adjacent road has a four-lane traveled way. 


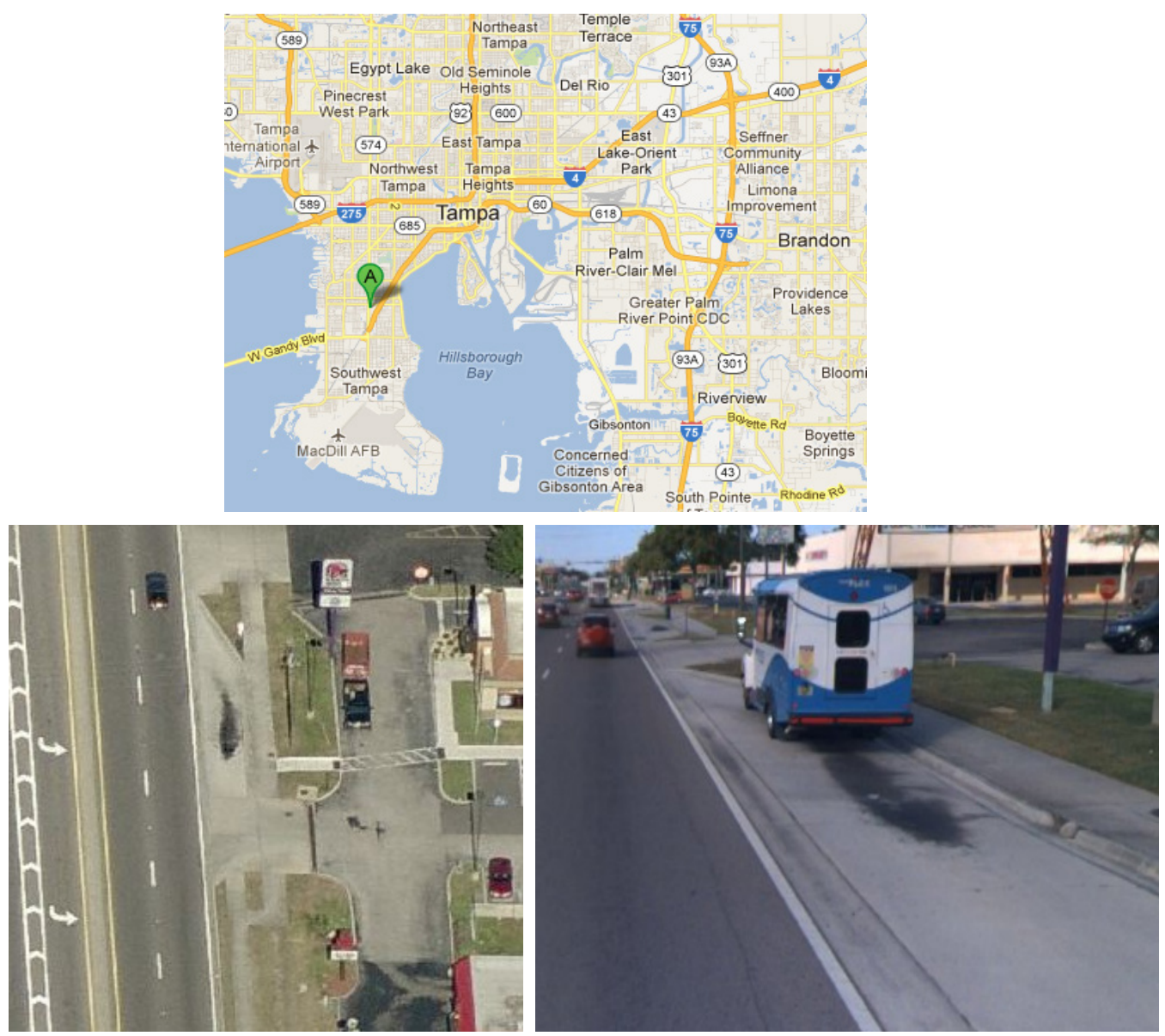

Figure 3-11: Bus Pullout Bay on Dale Mabry Hwy at Britton Plaza

East MLK Blvd at Riga Blvd: This bus pullout bay is located on a six-lane divided highway (E. MLK Blvd or SR 574). The speed limit of the facility is $50 \mathrm{mph}$. The bus stop has the standard amenities, including a shelter, benches, and bins. Delineation on this bus pullout bay could be improved by installing pavement markings with the, "bus only" text. Figure 3-12 shows this bus bay. 



Figure 3-12: Bus Pullout Bay on MLK Blvd at Riga Blvd

\section{Study Sites in Lee County}

US 41 at Williams Rd: This bus pullout bay is located on US 41 near Williams Rd in the southbound direction. The posted speed limit is $55 \mathrm{mph}$ and the highway is six-lane divided highway. The bus stop has all the standard amenities and it is well delineated. This bus pullout bay is located at the beginning of a right-turn lane which causes weaving between the merging bus and the turning traffic. For these situations, active signs such as in-bus LED signs and roadside YTB signs with flashers are recommended. Since this bus bay is not physically constrained the bus may use part of the right-turn lane as the acceleration distance. However, buses are not allowed to travel onto right turn lanes. This bus pullout bay can be observed in Figure 3-13.

US 41 at Island Park Rd: This pullout bay is located in the northbound direction on US 41, downstream of Island Park Rd. The bus stop provides only a bench with no shelter or bin. Delineation for this bus stop is strongly recommended. The posted speed limit for the facility is $45 \mathrm{mph}$. There is a bicycle facility but it is not indicated within the pullout bay. This bus bay can be observed in Figure 3-14. 

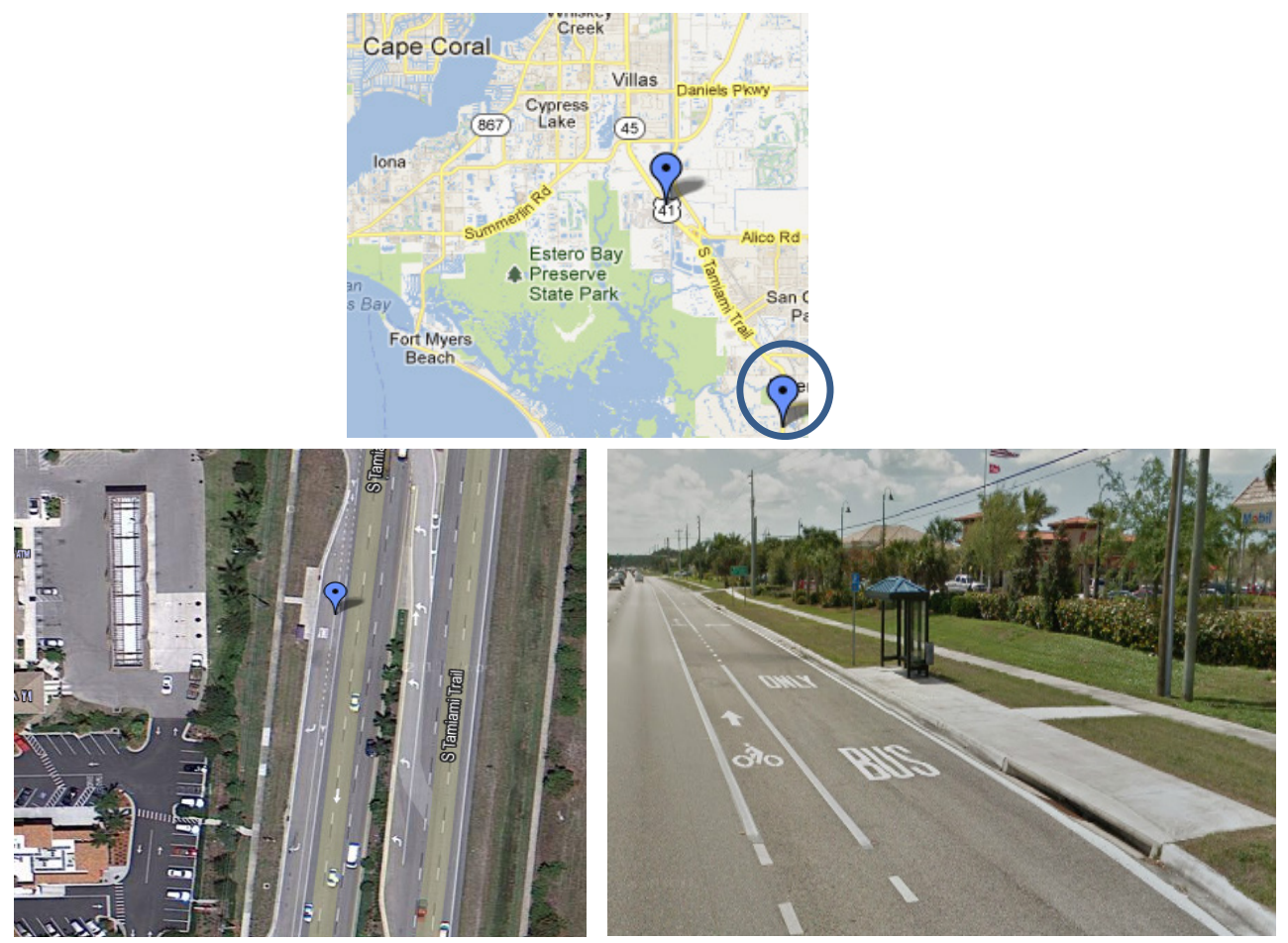

Figure 3-13: Bus Pullout Bay on US 41 at Williams Rd

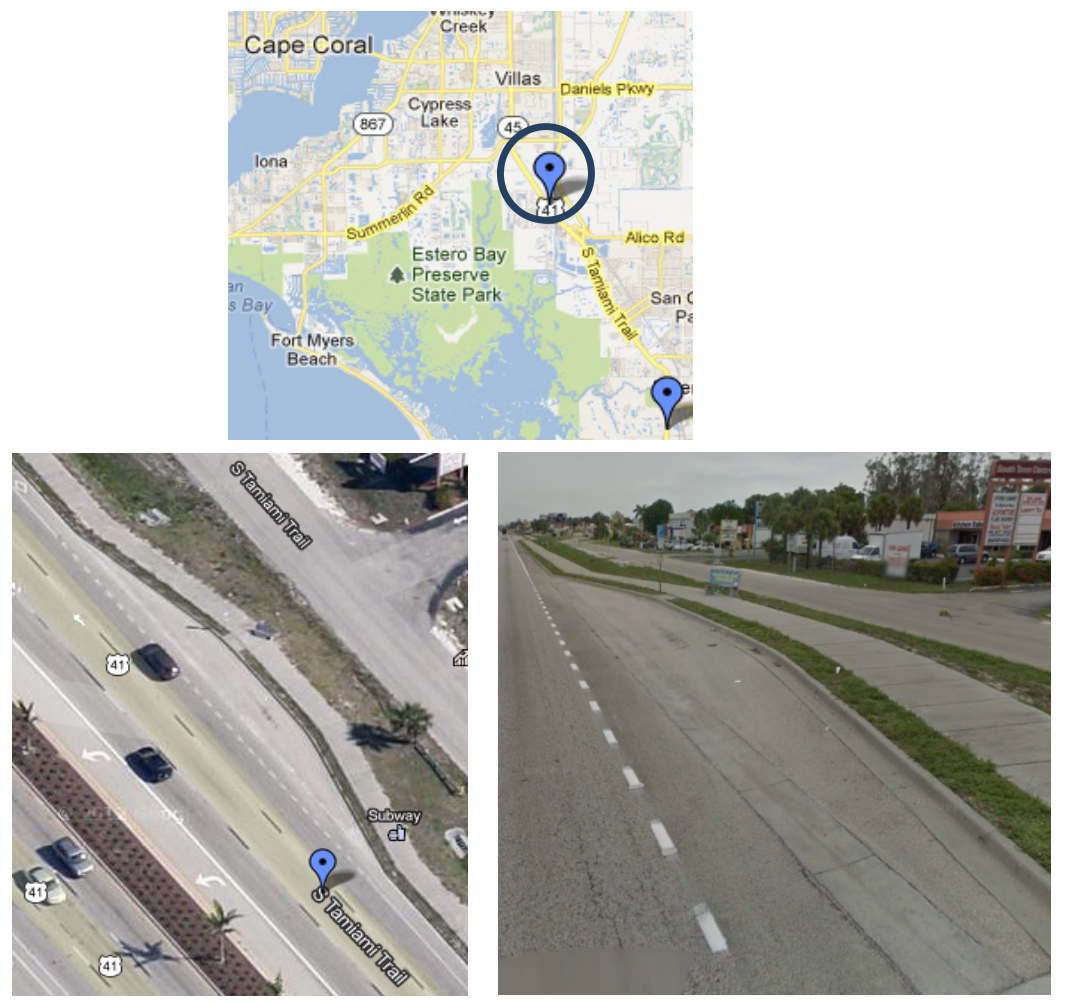

Figure 3-14: Bus Pullout Bay on US 41 at Island Park Rd 


\section{Chapter 4 \\ Data Collection and Analysis}

\section{Bus Pullout Bay Geometry}

The geometric characteristics of the study sites were analyzed using GIS data, aerial views, and site visits. GIS layers with bus stops were obtained from the participating transit agencies. The existing data was updated and verified with aerial imagery and site visits. Each pullout bay was measured and analyzed according to the key design elements as specified in Chapter 2. The geometric characteristics pertaining to the merging operation of the bus pullout bay were summarized in the acceleration distance parameter. Speed limits and other design features were collected and geo-referenced for future use.

Based on the collected information, the overall mean acceleration distance was $70.17 \mathrm{ft}$. This will allow merging speeds between 35 and $50 \mathrm{mph}$ for $4 \mathrm{fps}^{2}$ and $8 \mathrm{fps}^{2}$ acceleration rates respectively. Figure 4-1 presents a summary of the mean acceleration distance by speed limit. It can be observed that the bus bay design allows for more acceleration distance at higher speed limits.

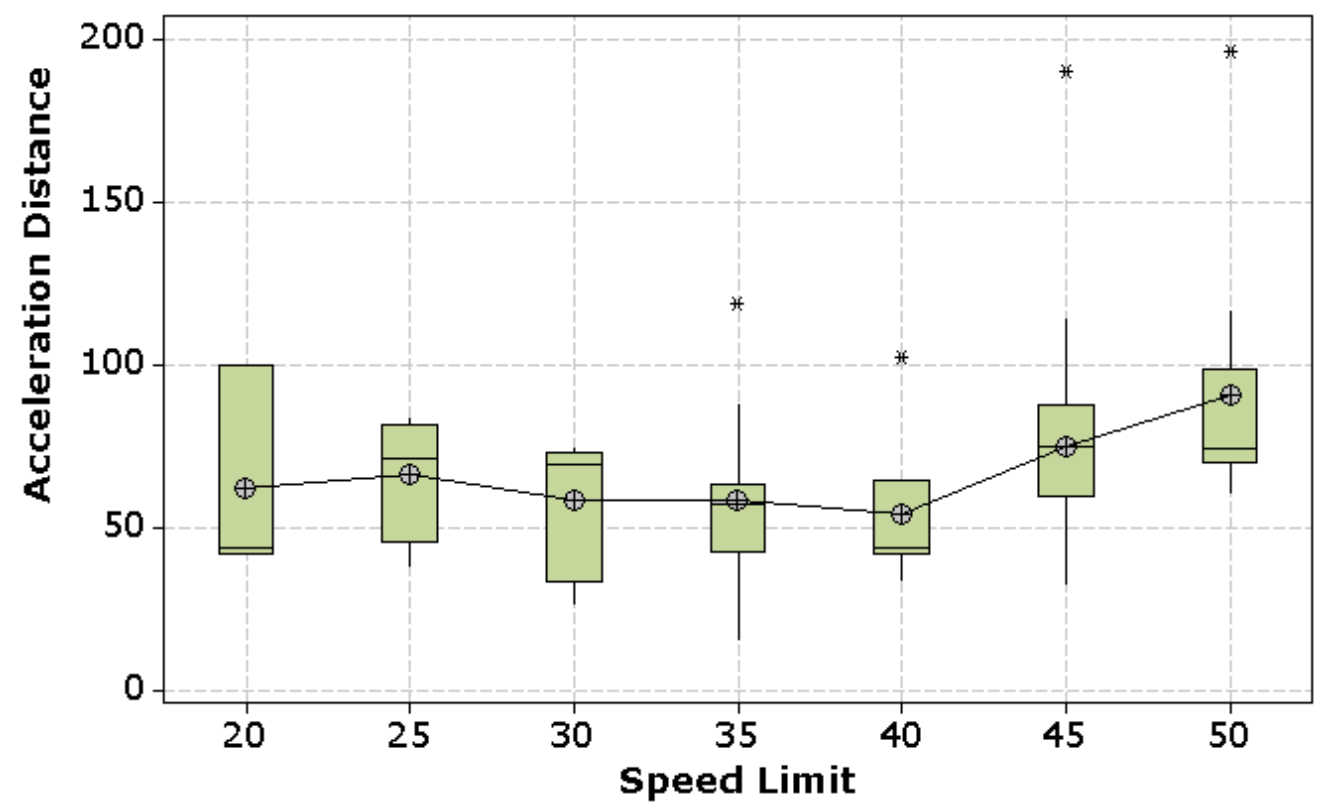

Figure 4-1: Boxplot of Acceleration Distance by Speed Limit

The performance measure for the bus bays was established as the minimum of the calculated re-entry speed and the speed limit of the facility, using a conservative acceleration rate of $4 \mathrm{fps}^{2}$ and a moderate to high acceleration rate of $8 \mathrm{fps}^{2}$. Figure 4-2 presents the performance of the bus pullout bay design. The performance was calculated as the ratio of the re-entry speed to the through-direction speed limit. A ratio of 100 percent indicates that the bus bay pullout bay design allows the bus to reach the target through speed. For the conservative acceleration scenario, 47 percent of the bus pullout bays are 
below the 80 percent line (re-entry speed is 80 percent of the speed limit). With the high acceleration rate scenario, only 4.7 percent are below the 80 percent line.

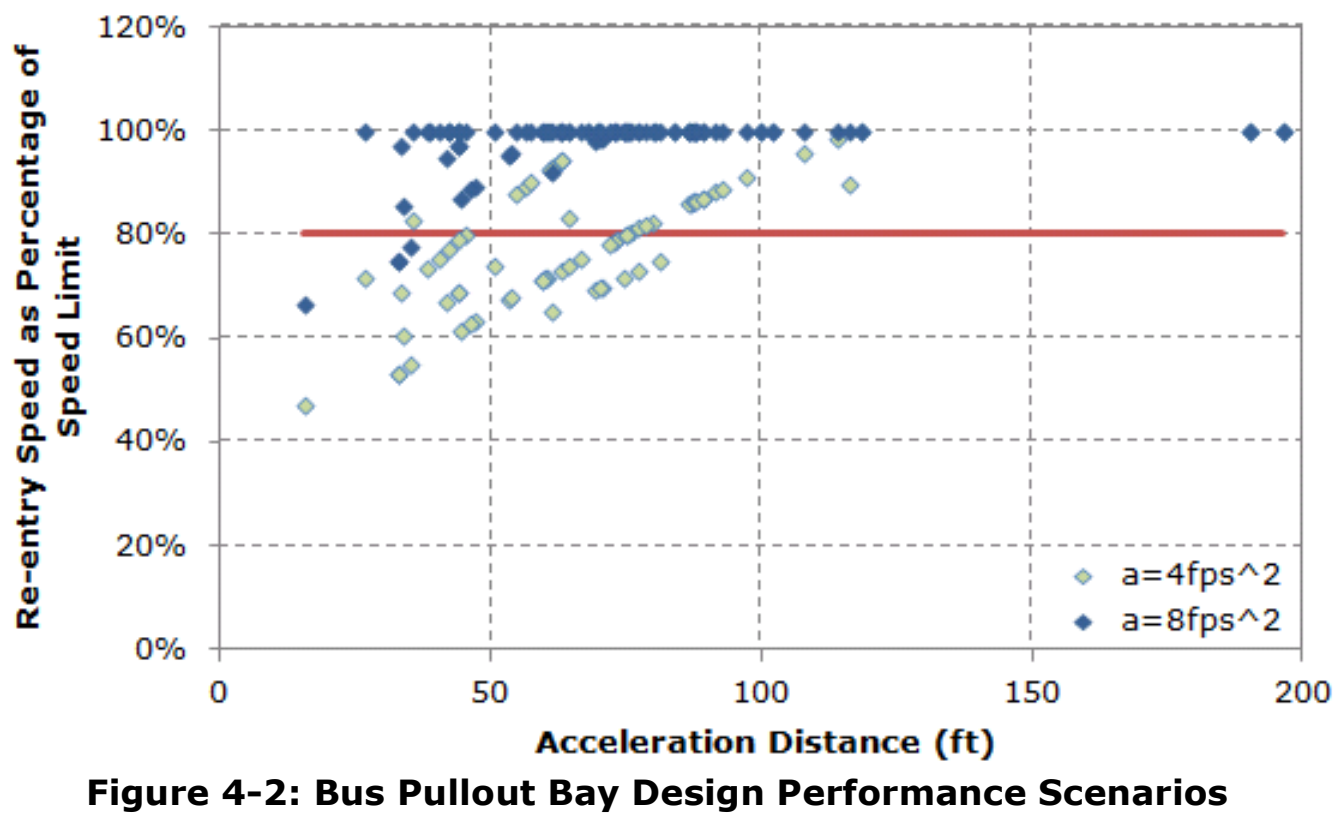

\section{Field Data Collection}

Data collection equipment included a mast with a high definition video camera located on top. The camera height was set to $25 \mathrm{ft}$. The mast and the equipment were transported to the data collection site using the University of South Florida's College of Engineering cargo van. An example of a data collection station in the field is shown in Figure 4-3.

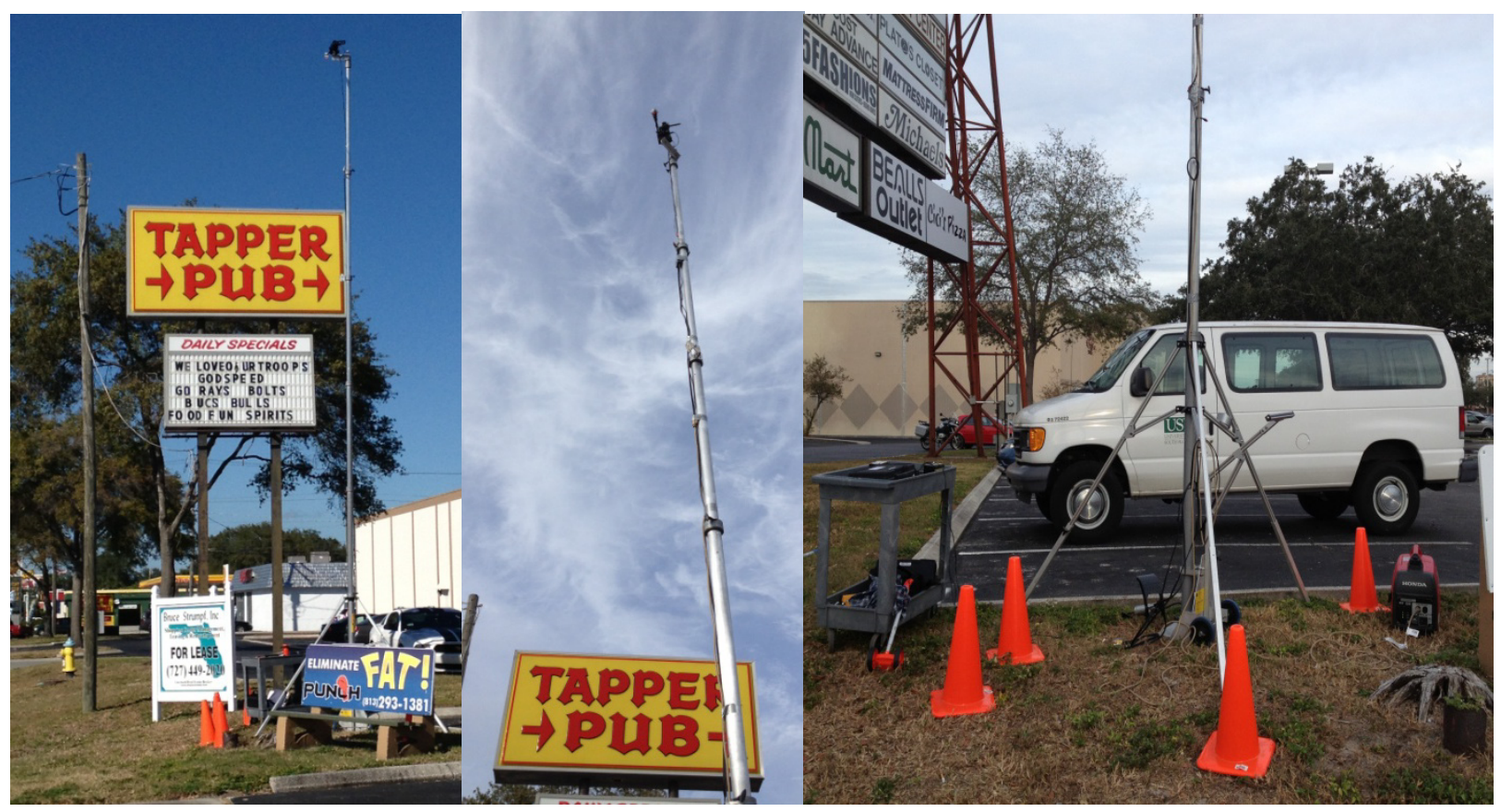

Figure 4-3: Data Collection Equipment 
Observations for the study were of merging maneuvers for transit buses in the field. Accumulating a sufficient number of observations for analysis took a significant amount of time, since not all merging maneuvers were valid. Also for this reason, no controlled runs or tests were performed.

To accept a merging maneuver as valid, the bus has to be in position to merge within the bus pullout bay, and it has to request the right-of-way by activating the regulatory turning lamps. In this way, the bus is in compliance with the Florida statute 316.0815 (YTB law) which states:

"The driver of a vehicle shall yield the right-of-way to a publicly owned transit bus traveling in the same direction which has signaled and is reentering the traffic flow from a specifically designated pullout bay."

A bus waiting in the bus pullout bay with no turning indication and then merging was not considered a valid sample. Obtaining significant valid samples was a challenging task since it depended upon bus frequency, ridership at a particular bus stop, and traffic conditions at the moment of merging back into traffic. The most active bus stop was located at Britton Plaza on S. Dale Mabry Hwy in Hillsborough County. This bus stop was used by several routes and transit services as a staging area and thus had a considerable amount of bus traffic to produce a significant number of valid samples.

\section{Performance Measures}

The main performance measure was the yield-to-bus behavior indicator defined as follows:

- Yield: If the merging maneuver ended in a vehicle yielding the right of way to the bus. This may include vehicles performing safe lane changes and allowing the bus to merge back into traffic.

- Gap: If the bus had to wait for an acceptable gap in traffic to merge back in. This is the complement of the yield indicator.

The sum of the number of maneuvers ending in yield and the number of maneuvers ending in a gap equals the total of observations. Figure 4-4 shows a merging maneuver ending in a gap and Figure 4-5 shows a merging maneuver ending in a yield action.

The operational performance measure was the re-entry time defined as the interval between the time the bus activates the turning signal and when the rear bumper exits the acceleration taper. Figure 4-4 presents an example of the re-entry time for a maneuver ending in a gap. In part $A$ of Figure 4-4, a stopped bus is preparing to merge back into traffic by activating its turning lamps. In part $B$, after 17 seconds, the bus is still waiting for a gap in traffic or a yield action. In part $C$, a gap is available, and the bus proceeds to merge back into traffic. Part $D$ shows the end of the merging maneuver. 


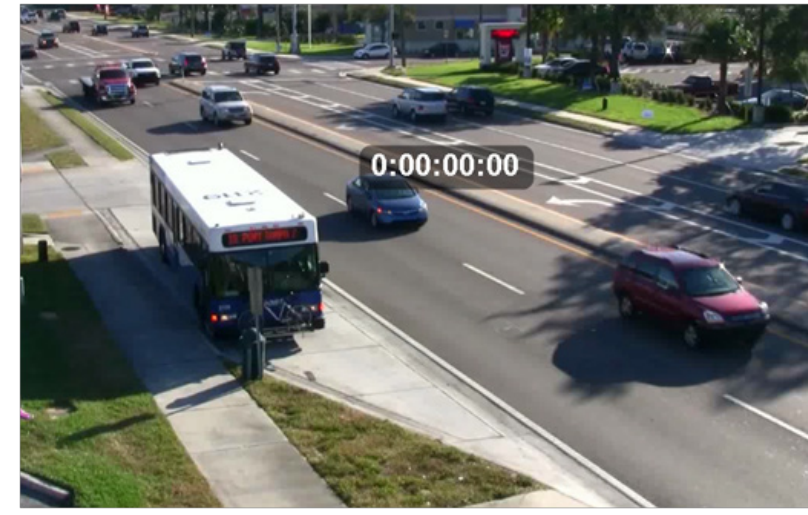

a. Bus turned on turning lamps

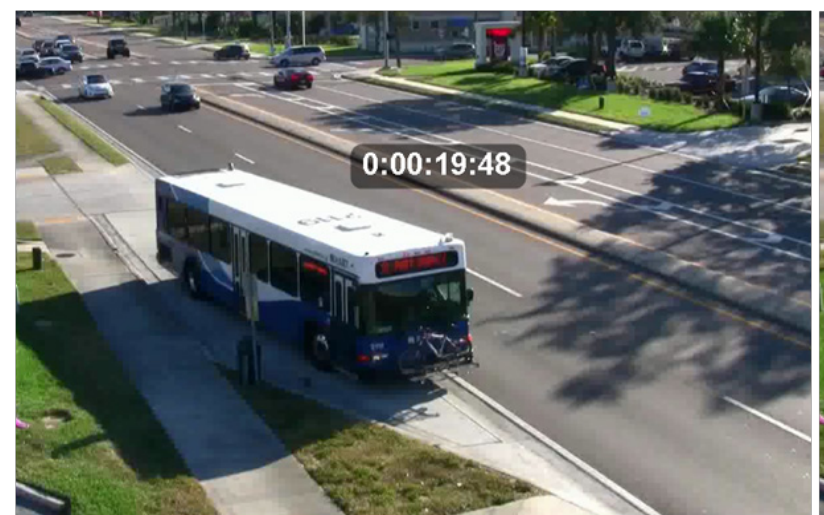

c. Bus starts merging

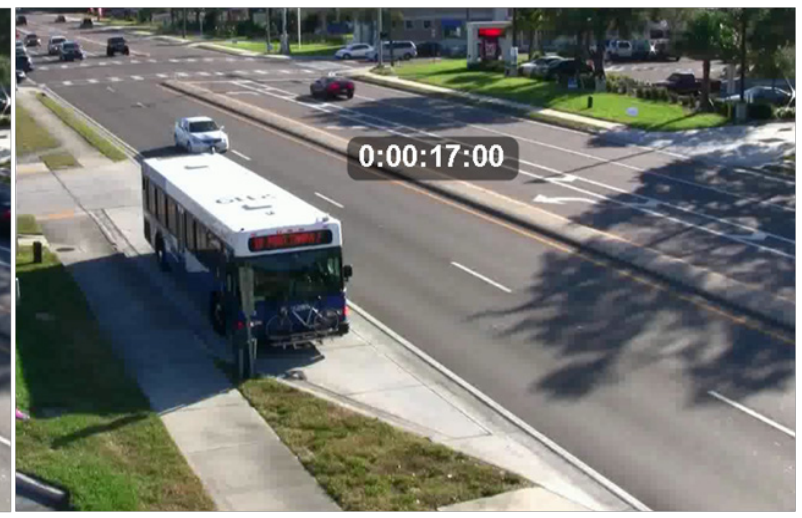

b. At $\mathrm{t}=17 \mathrm{sec}$. there is an acceptable gap

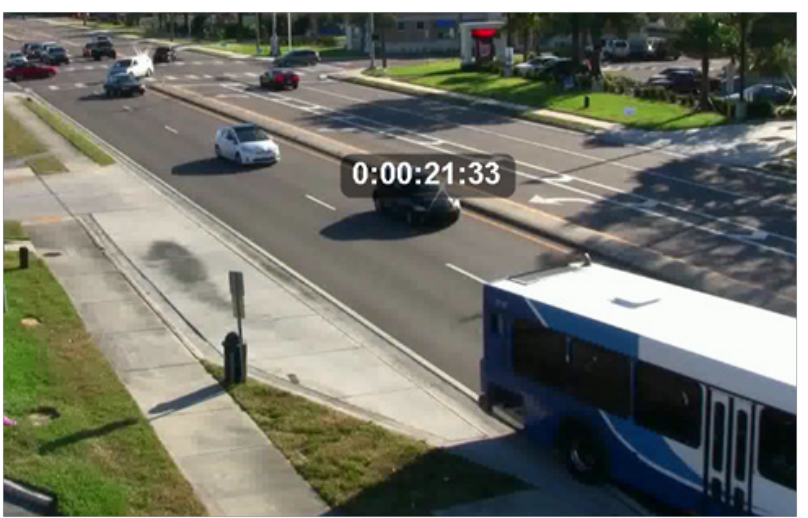

d. Bus finishes merging at $\mathrm{t}=21.33 \mathrm{sec}$.

Figure 4-4: Example of Merging Maneuver Ending in Gap and Re-entry Time

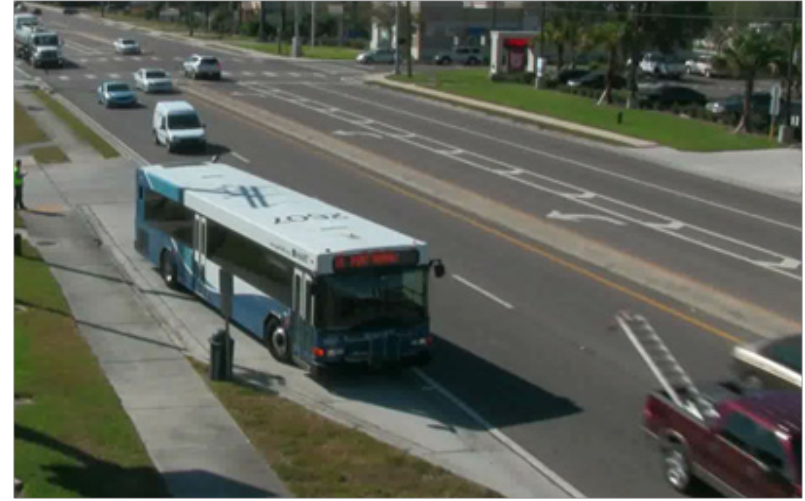

a. Vehicle yielding to the bus entering traffic

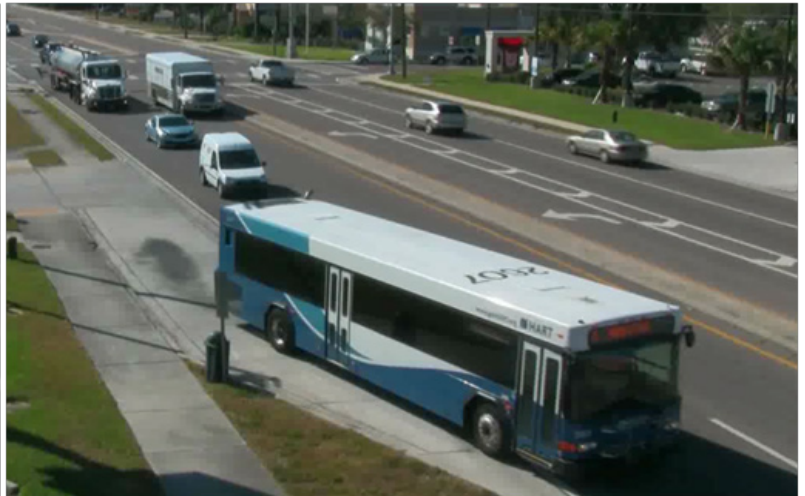

b. Bus merging back into traffic

Figure 4-5: Example of Merging Maneuver Ending in Yield

Safety was assessed by performing traffic conflict counts. A traffic conflict or near-crash is defined as a traffic incident involving the interaction of two or more motor vehicles, where one or both drivers must take an evasive action (e.g., sudden braking) to avoid a collision. 
Near-crashes are referred to as surrogate measures of crash frequency, or crash rates. Table 4-1 presents the main conflict related to YTB operation.

Table 4-1: Traffic Conflict Diagrams for Safety Evaluation

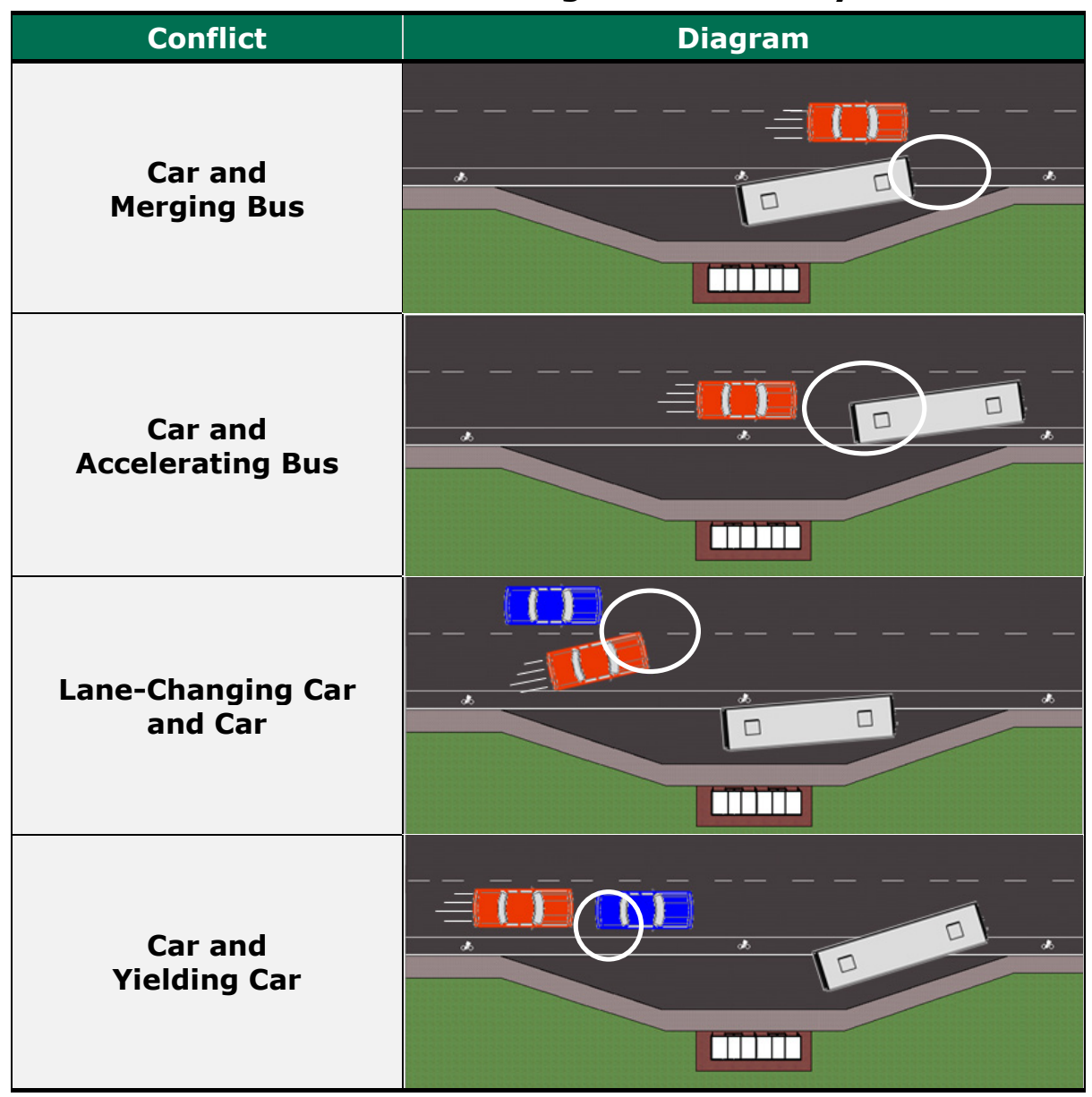

Table 4-1 shows the main traffic conflicts associated with YTB operations. Such conflicts were defined in previous studies[6] and are described as follows:

- Car and Merging Bus: This is a direct conflict involving a bus leaving a bus bay or right-turn lane in which the bus gets too close to a car in the travel lane.

- Car and Accelerating Bus: This is a direct conflict in which a bus enters the traffic lane at low speed and the car behind has to brake to avoid a collision.

- Lane-Changing Car and Car: This is a secondary conflict caused by a car in the travel lane performing an unsafe lane change in an attempt to avoid yielding to a bus entering the traffic.

- Car and Yielding Car: This is a secondary conflict in which a car that yielded the right-of-way to the bus experiences a conflict with a close-following car. 


\section{Data Analysis}

A total of 42 valid samples were obtained from the bus pullout bay at Britton Plaza in Hillsborough County over a period of two months. Out of the 42 observed maneuvers, 28 ended in the bus waiting for a gap in traffic (No-Yield) and 14 ended in vehicles yielding the right of way to the merging bus (see Figure 4-6). The percent of maneuvers that ended in a yield was 33 percent.



Figure 4-6: Observed Yield-to-Bus Behavior

The re-entry time was calculated based on the time the bus turning lamps were activated. The overall re-entry time was 36 seconds, with a standard deviation of 32seconds. The average re-entry time for merging maneuvers ending in yield was 29 seconds, with a standard deviation of 13 seconds. For non-yield maneuvers, the average re-entry time was 39 , with a standard deviation of 13 seconds. A box plot of the re-entry time by yield-to-bus behavior (yield, no-yield) is presented in Figure 4-7. It can be observed that the variance of the re-entry time reduced when motorists yield to the bus. This can have a positive effect on transit travel time reliability and schedule adherence. Another comparison is presented in Figure 4-8 using the histograms for re-entry time for both merging scenarios. It can be observed that for merging maneuvers ending in yield, the re-entry time has a shorter range of variation.

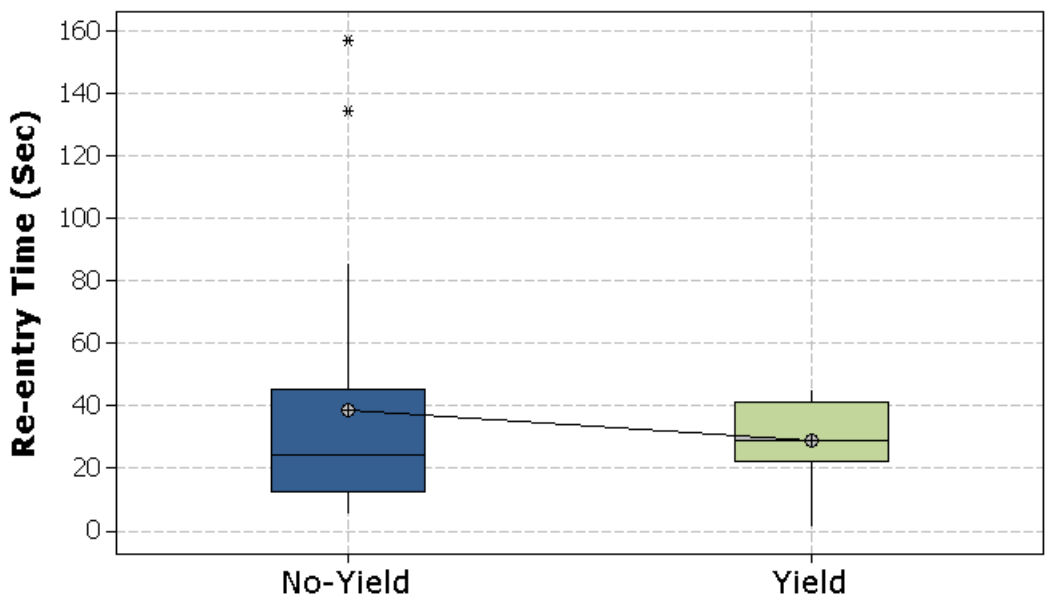

Figure 4-7: Box Plot of Re-entry Time by YTB Behavior 




Figure 4-8: Histogram of Re-entry Time by YTB Behavior

Safety was evaluated by using conflict counts. It was found that 93 percent of the maneuvers presented no traffic conflict. Out of the 42 samples, three maneuvers presented traffic conflicts. There were two observed conflicts involving a car and an accelerating bus and one observed conflict between a lane-changing car and another car. 


\section{Chapter 5 \\ Conclusions and Recommendations}

\section{Conclusions}

In this project, yield-to-bus roadside signage was designed and proposed for future implementation. Also, geometric factors of bus pullout bays design were collected, analyzed, and geo-referenced for future use. The study of roadside treatments, an analysis of the geometric characteristics of bus pullout bays, and field data collection were aimed at achieving the following objectives:

- Identify the critical design features and prevailing conditions affecting the safety of the merging maneuvers of buses entering traffic from bus pullout bays.

- Design a set of roadside treatments or traffic control devices to promote YTB behavior at bus pullout bays.

- Provide recommendations for implementation, and evaluation of YTB traffic control devices on the State Highway System.

In addition, video analysis tools and an innovative data collection method were developed. Based on the field data collection and analyses, the following conclusions were drawn:

- The preferred traffic control device to support the YTB law is the roadside sign. Roadside signs provide a more direct message to the motorists than pavement markings.

- The average acceleration distance was $70 \mathrm{ft}$. with a moderate acceleration rate of 4 $\mathrm{fps}^{2}$. This will allow buses to reach a re-entry speed of $35 \mathrm{mph}$.

- Based on detailed observations at the one of the test sites, the percentage of merging maneuvers that ended in a yield was found to be 33 percent. However, 67 percent of those maneuvers ended in the transit bus waiting for an acceptable gap in traffic.

- The overall average re-entry time was 36 seconds in this study. For merging maneuvers ending in yield, the average re-entry time was 29 seconds. For merging maneuvers where the motorist did not yield to the bus, the average re-entry time was 39 seconds. Therefore, an average operational efficiency in transit operations of up to 25 percent could be achieved as more motorists yield to the bus.

- $\quad$ The standard deviation for the re-entry delay for maneuvers ending in yield was 13 seconds, while for maneuvers with no-yield the standard deviation was 39 seconds. This can have a significant influence on travel time reliability.

- The percentage of maneuvers with conflicts was 93 percent. Two types of conflicts were observed, car and accelerating bus, and lane-changing car and car. 


\section{Recommendations}

- It is recommended that transit agencies incorporate some traffic features as part of their GIS database. This can include whether the bus stop is in bus bay, or in a turning lane, bus pullout bay geometry, proximity of upstream access point, etc. This can help to provide a better evaluation for transit safety and operations with respect to traffic.

- YTB sign placement should meet the guidelines contained in the MUTCD. YTB signs are recommended to be placed at $100 \mathrm{ft}$ upstream from the beginning of the bus bay when the posted speed limit is $45 \mathrm{mph}$ or less.

- It is recommended that the sign messages for YTB roadside treatments are tested using a survey instrument to ensure that the sign wording is interpreted correctly.

- For testing purposes, it is recommended the use of solar-powered flashing beacons with a non-intrusive detection system such as the one proposed using LIDAR devices. For field implementation a more robust solution using sensors can be developed.

- It is recommended to incorporate additional transit agencies for the field testing of the YTB roadside sign with flashers.

- Accident data from transit agencies can be a valuable source of information for roadway design improvement. It is recommended to standardize transit incident reporting, especially location information in the form of milepost or geographic coordinates. 


\section{References}

[1] H. Harrison and I. Audirac, Accessing Transit: Design Handbook for Florida Bus Passenger Facilities, Tallahassee: Florida Department of Transportation Public Transit Office, 2008.

[2] FHWA, Manual on Uniform Traffic Control Devices, Washington D.C.: U.S. Department of Transportation, 2009.

[3] AASHTO, A Policy on Geometric Design of Highway and Streets, Washington D.C.: American Association of State Highway and Transportation Officials, 2004.

[4] K. Fitzpatrick, K. Hall, D. Perdinson and L. Nowlin, TCRP Report 19: Guidelines for the Location and Design of Bus Stops, Washington D.C.: TRB, National Research Council, 1996.

[5] I. Kittelson \& Associates, I. KFH Group, I. Parsons Brinckerhoff Quade \& Douglass and K. Hunter-Zaworski, "TCRP Report 100 Transit Capacity and Quality of Service Manual 2nd Edition," Transportation Research Board, Washington, D.C., 2003.

[6] A. Fabregas, P.-S. Lin, E. Gonzalez-Velez, A. Datz and H. Zhou, "Safety and Operational Assessment of Yield-to-Bus Electronic Warning Signs on Transit Buses," Transportation Research Record: Journal of the Transportation Research Board 2218, pp. 1-9, 2011. 